\title{
Gradhiva
}

GRADHIV

Revue d'anthropologie et d'histoire des arts

$1 \mid 2005$

Haïti et l'anthropologie

\section{La création plastique et le tournant ethnologique en Haïti}

Creation in the plastic arts and the "ethnological turning point» in Haiti

Carlo Avierl Célius

\section{(2) OpenEdition}

Journals

Édition électronique

URL : http://journals.openedition.org/gradhiva/301

DOI : 10.4000/gradhiva.301

ISSN : 1760-849X

Éditeur

Musée du quai Branly Jacques Chirac

Édition imprimée

Date de publication : 1 mai 2005

Pagination : 71-94

ISBN : 2-915133-08-5

ISSN : 0764-8928

Référence électronique

Carlo Avierl Célius, "La création plastique et le tournant ethnologique en Haïti », Gradhiva [En ligne],

1 | 2005, mis en ligne le 10 décembre 2008, consulté le 19 avril 2019. URL : http://

journals.openedition.org/gradhiva/301 ; DOI : 10.4000/gradhiva.301

Ce document a été généré automatiquement le 19 avril 2019.

(c) musée du quai Branly 


\title{
La création plastique et le tournant ethnologique en Haiti
}

Creation in the plastic arts and the "ethnological turning point» in Haiti

\author{
Carlo Avierl Célius
}

1 De nouveaux types de relation se nouent entre création artistique et anthropologie à la fin du XIX et dans les premières années $\mathrm{du} \quad \mathrm{xx}^{\mathrm{e}}$ siècle. En Haïti, cette reconfiguration donne naissance à un mouvement désigné sous le nom d' indigénisme, qui, selon l'analyse $\mathrm{du}$ sociologue Claude Souffrant ${ }^{1}$, a pris les dimensions d'une véritable révolution culturelle. Un point de vue que l'anthropologue Michel-Rolph Trouillot n'est pas loin de partager. Cependant,

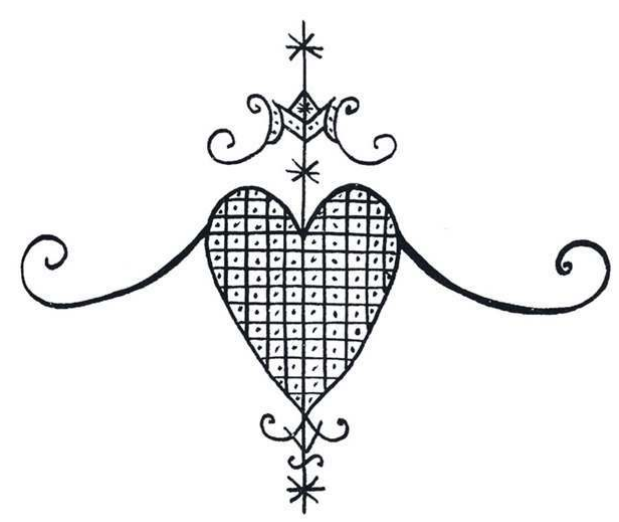
contrairement à Souffrant, il estime que le

phénomène ne dérive pas de la seule initiative de Jean Price-Mars. Il relève au moins deux démarches distinctes mais convergentes: celle, littéraire, de jeunes bourgeois contestataires, fondateurs de revues, dont la Revue Indigène (1927-1928), et celle, ethnographique, à visée sociale, de Price-Mars². L'indigénisme, que l'auteur distingue de la négritude et du noirisme (Trouillot 1986), est donc au départ, pluriel. Et il le restera. Au point qu'il faut chercher à le saisir dans ses mouvances et dans ses métamorphoses continuelles. Ainsi se comprend le fait qu'il ait produit des phénomènes aussi divers que l'art naïf ${ }^{3}$ ou le courant musical appelé «musique racine », dont Boukman Eksperyans est le groupe emblématique (Trouillot 1993).

2 À cette approche nuancée, mais globalisante, s'oppose celle de Georges Castera-fils (1997) qui, dans un même souci de réévaluation de l'indigénisme, propose qu'on s'en tienne à une délimitation stricte du mouvement. Selon lui, le mot et la chose sont une invention, 
non pas de l'équipe de la Revue Indigène, mais de celle de la revue Les Griots (1938-1939) qui, rappelons-le, est plus directement sous l'influence de Price-Mars ${ }^{4}$. L'art naïf reste-t-il, dans cette seconde perspective, un avatar de l'indigénisme?

3 Pour Danielle Bégot (1988), la peinture naïve «s'inscrit dans le sillage » de l'indigénisme «mais pas dans sa mouvance». Michel-Philippe Lerebours quant à lui, à la suite de Philippe Thoby-Marcelin, distingue nettement un courant pictural proprement indigéniste qui précède l'avènement de l'art naïf (Thoby-Marcelin 1956 ; Lerebours 1989). Et, entre les deux courants, Félix Morisseau-Leroy (1955a : ${ }^{5}$ ) martelait déjà que la différence est radicale. En effet, leur mode d'instauration respectif diffère, de même que leur démarche d'ensemble et les œuvres réalisées.

4 L'art naï en tant que genre résulte des nouvelles relations nouées entre art et anthropologie à la fin $\mathrm{du} \mathrm{XIX}^{\mathrm{e}}$ siècle et au début $\mathrm{du} \mathrm{Xx}^{\mathrm{e}}$, et son avènement en Haïti ne procède pas pourtant de l'indigénisme; il le déborde, le subvertit et en signale ainsi les limites, observables jusque dans la difficulté éprouvée par «l'école haïtienne d'ethnologie » à l'accompagner, à le penser ou, tout simplement, à l'approcher.

\section{Courants artistiqueset visions anthropologiques}

\section{Le projet d'une « modernité indigène »}

5 C'est bien dans le cadre du mouvement de reconsidération des valeurs constitutives de la culture nationale, amorcé au début $\mathrm{du} \mathrm{xx}^{\mathrm{e}}$ siècle que naît le courant pictural qualifié d'indigéniste. Deux écrivains, Jacques Roumain, futur ethnologue, et surtout Philippe Thoby-Marcelin encouragent Pétion Savain qui manifeste des dispositions pour la peinture. Le peintre tient sa première exposition en 1932 et très vite d'autres artistes se joignent à lui et tous travaillent à fonder une modernité artistique indigène.

Philippe Thoby-Marcelin explicite le projet dans sa présentation d'une exposition de Savain en 1934. Avec cet artiste, soutient-il, naît « une peinture haïtienne », en ce que son œuvre, selon les mots de Proudhon, est " actuelle, concrète... », " exprime les idées du temps et [...] parle la langue du pays ». Comme dans le domaine littéraire, cela n'implique en rien un enfermement sur soi, car être de son temps c'est se mettre à l'écoute du monde et être en phase avec des tendances contemporaines. Voilà pourquoi la peinture de Savain, selon Thoby-Marcelin, «utilise toutes les richesses de la peinture française moderne ", non point pour refaire du Cézanne, du Picasso ou du Modigliani, mais pour en tirer des leçons de leur démarche, comme ces artistes eux-mêmes en ont tiré de «la sculpture nègre primitive». Ainsi «la peinture française moderne» rend à la peinture haïtienne "un service égal à celui qu'un Modigliani doit à la sculpture nègre ». C'est, insiste Thoby-Marcelin, qu'il n'y a «... pas de progrès, sans échanges de peuple à peuple, de race à race. La connaissance, nous fait remarquer Jean Rostand "est un produit foncièrement hybride" ».

7 Dans ce projet d'une modernité indigène, confirmé par Savain lui-même (1936), l'« indigénéité », ainsi que le laisse comprendre un article de Marcello de Sylva de 1938, réside essentiellement dans le choix des thèmes. La «couleur locale» tient essentiellement au traitement du paysage mais aussi à la place accordée au paysan, à ses coutumes, ses misères et ses infirmités. 
8 Mais l'hybridité dont parle Thoby-Marcelin n'est en rien une nouveauté. Elle correspond à la pratique des artistes du xix ${ }^{\mathrm{e}}$ siècle. Eux aussi traitaient de thèmes locaux en utilisant genres et styles des beaux-arts en vigueur à leur époque. Les artistes des années 1930 croyaient avoir été les premiers à représenter le paysage local alors qu'il est présent dans l'estampe et la peinture depuis l'époque coloniale. Jaymé Guilliod, sculpteur et dessinateur actif vers le milieu du XIX ${ }^{e}$ siècle (Célius 1996), en fournit une illustration avec son Fond-Calalou (Fig. 2), "demeure délicieuse enfermée dans un nid épais de hauts palmistes, au milieu de la campagne sévère et volcanique de Jacmel, résidence chérie de Faustin Ier, où la Présidence est allée le prendre, et où il va, avec une petite cour d'amis dévoués, oublier les soucis, les fatigues et les préoccupations de la puissance ». Toute la charge affective et symbolique investie dans ce paysage - à la fois lieu de souvenirs personnels de Guilliod ( «un dessin qui m'a rappelé de biens doux et de biens amers souvenirs d'enfance ", souligne-t-il) et d'histoire nationale (en ce qu'il est habité par l'empereur Faustin Soulouque) - n'est pas sans rappeler certaines œuvres des peintres de la tendance indigène. Pensons au sentiment nationaliste qu'entendait exprimer Georges Remponeau à travers Le Lamentin (1940) ou encore Jean Parisot avec son Sémaphore (ca 1937) ${ }^{6}$. Cela dit, le courant pictural des années 1930 marque une différence par rapport au XIX ${ }^{e}$ siècle. L'éventail des thèmes susceptibles d'être traités s'est élargi. Portrait et sujets historiques ne conservent guère leur ancienne prééminence, la préférence allant de plus en plus à des sujets puisés dans le monde paysan et "populaire » urbain associés au nouveau critère de valorisation : l'haïtianité. Ce qui constitue une transgression, même sous le mode folklorisé, dans le domaine des beaux-arts, jusque-là espace symbolique d'auto-représentation des élites remplissant une fonction de différenciation sociale (Célius 2000).

9 Au XIX ${ }^{e}$ siècle, le combat des artistes et l'évaluation de leurs œuvres reposaient sur d'autres paramètres. On cherchait à fonder l'« Art en Haïti » plutôt que l'« art haïtien ». La démarche de Guilliod le montre bien. Son Fond-Calalou est l'un des vingt dessins accompagnés de cinq lettres qu'il publie dans l'hebdomadaire parisien, L'Illustration, de 1849 à 1852. Il engage explicitement un triple combat : la défense du gouvernement de Faustin Soulouque, largement ridiculisé à l'étranger, dans diverses publications (articles, livres, caricatures, en l'occurrence celles de Daumier et de Cham), et jusque sous la plume de Victor Hugo et de Karl Marx ; la défense de son pays dénigré et celle de sa "race » infériorisée. Trois combats en un, menés au nom du progrès de « La Civilisation » en Haïti. Et c'est dans le cadre du paradigme civilisationnel que ses envois, acceptés par la rédaction de L'Illustration, sont évalués. Non seulement Guilliod a réussi à faire publier ses dessins, mais la rédaction a fini par le soutenir au fur et à mesure de sa correspondance, apportant ainsi une note dissonante dans le concert de dénigrement dont le gouvernement de Soulouque était accablé. Guilliod restitue des visages d'hommes et de femmes politiques de son pays (Fig. 3), invitant à les comparer avec des hommes et femmes politiques d'autres pays montrés dans les pages du même périodique. La réussite $d u$ procès d'humanisation qu'il a engagé doit beaucoup à l'évaluation positive de son talent d'artiste, sa maîtrise technique, au fait que ses œuvres peuvent tout à fait être comparées à celles d'artistes européens reconnus. Autant de facteurs qui concourent à prouver son aptitude personnelle à participer à l'œuvre de "Civilisation", qu'il partage avec le peuple auquel il appartient, le gouvernement et la « race » qu'il défend.

L'enjeu de l'opération est considérable. Une certaine collusion entre anthropologie et théories de l'art avait abouti, au XvIII ${ }^{e}$ siècle à l'établissement du critère esthétique dans 
la hiérarchisation des races. Le "noir » est alors placé après le singe au bas d'une échelle au sommet de laquelle trône le "blanc ", incarnant la beauté, sous les traits d'une belle tête de sculpture grecque, une tête d'Apollon de préférence. Cette échelle, que l'on retrouve dans les planches de physiognomonie destinées aux cours de dessin, sera reprise par les théoriciens du racisme scientifique. Un Victor Courtet de l'Isle, par exemple, l'un des premiers d'entre eux en France, publie, à la fin des années 1840, son Tableau ethnographique du genre humain (1849), dont une première mouture avait paru dans L'Illustration (1847) (cf. p. 99)7. D'ailleurs l'un des " portraits » de Toussaint Louverture, le plus connu, dessiné dans les années 1820 par Nicolas-Eustache Maurin est à l'évidence inspiré de ces tables (Fig. 4)7. On comprend le défi lancé à Guilliod chargé de réaliser, à la demande de l'Empereur, une statue de Toussaint Louverture, inaugurée à l'occasion de la cérémonie du sacre en 1852.

11 L'entreprise de Guilliod n'est pas isolée. La réflexion théorique sur la création plastique et sur l'esthétique passe, au cours du xix $x^{\mathrm{e}}$ siècle, par la discussion du critère esthétique dans la hiérarchisation des races. Sous la plume de De Vastey (1816:20-22), de Saint-Rémy des Cayes en 1853, d'Anténor Firmin en $1885^{8}$ ou de Jean Price-Mars en $1907^{9}$, elle participe d'un incessant combat antiraciste qui conduit les auteurs aux frontières d'un certain relativisme. Mais le paradigme civilisationnel dans lequel s'inscrivent leurs démarches les place dans un évolutionnisme qui les incite surtout à chercher à repousser les limites de l'universalité, en tout cas ce qui était défini comme tel. Il s'agit au fond d'apporter la preuve de l'humanité de l'homme issu de l'esclavage et de «l'homme noir » en général. Il y a là une visée anthropologique qui prend en charge les différences pour autant qu'elles concourent à prouver l'humanité de tous les hommes. Aussi adopte-t-on une conception universalisante de l'art (beaux-arts) utilisée comme arme de combat. Mais les choses changent dans les premières années $\mathrm{du} \mathrm{xx}^{\mathrm{e}}$ siècle sous l'impulsion de la modernité artistique et de l'ethnographie. Désormais prévaut une conception particularisante de l'art où sont mis en avant des thèmes considérés comme étant l'expression de l'haïtianité.

Parmi ces thèmes, le vodou occupe une place de plus en plus significative. La comparaison avec le milieu du XIX siècle donne la mesure du changement survenu. Dans le numéro du 21 février 1852 de L'Illustration, parait, sous la plume d'un dénommé A. Pigeard, un reportage sur Haïti ayant pour titre "Une fête publique à Haïti ». L'auteur relate les festivités organisées à l'occasion du retour de Soulouque dans la capitale après une tournée dans le pays. Ces festivités consistent essentiellement en des « danses » vodou se déroulant dans des cabanes en feuillage dressées le long de la route jusqu'à un arc de triomphe éphémère, en bois, érigé à l'entrée de la ville, sur le chemin de la Croix-desBouquets. L'auteur décrit longuement une "danse grossière», une "danse sauvage venant directement d'Afrique, et autorisée par le gouvernement » à laquelle s'adonnent des campagnards descendus en grand nombre des mornes. Une gravure anonyme fige une séquence de cette danse (Fig. 5). Cette œuvre graphique, une des toutes premières représentations d'une scène vodou, n'est pas parvenue à restituer la grossièreté et la sauvagerie dont parle l'article (voir, à titre de comparaison, les dessins illustrant Magic Island de William Seabrook, 1929) ${ }^{10}$. Cependant, en accord avec l'argument soutenu dans le texte, le dessin, comme une photo de reportage, montre une danse qui se déroule sous une tonnelle, dans un espace ouvert, et qui atteste d'une pratique de plein jour, non clandestine. Ce que renforce l'angle de vue adopté par le dessinateur: la danse est représentée de l'intérieur, face à la rue, nettement décelable dans un arrière-plan qu'aucune foule n'obstrue. Adeptes et assistants - parmi lesquels figurent des 
personnages endimanchés dont deux en tenue militaire, attestant sans doute de la complicité des élites et des autorités établies - sont regroupés de part et d'autre de l'espace central où se tient une danseuse. Tout concourt à montrer que l'instant est exceptionnel : le personnage à genoux, qui vient en aide, les trois autres qui sont dans une attitude de déférence, l'activité empressée du groupe des trois femmes de droite. La danseuse au centre de la scène entre en possession. À cela, Guilliod répond, certes indirectement, en mettant en évidence, dans son envoi de 1852, la figure d'un religieux, l'abbé Belot (Fig. 6). Il souligne, dans sa lettre, l'action évangélisatrice de l'abbé qu'il traduit en dessin en campant un personnage dynamique, saisi en marche, et non dans une pose statique (comme pour les autres portraits du corpus), un livre, sans doute la Sainte Bible, en main, bien mis en évidence tant par sa proportion que par le jeu des contrastes. L'artiste suggère ainsi une action en cours, motivée par une volonté ferme et qui se déploie sans être contrariée. En d'autres termes, Soulouque encourage le développement de la religion chrétienne, répandant ainsi les bienfaits de « La Civilisation » dans le pays.

La dénonciation de l'état de barbarie dans lequel patauge Haïti, le pays du vodou, s'est intensifiée entre 1863 et 1889. Au cours de cette période s'organisent aussi les premières tentatives de campagne antisuperstitieuse menée par le clergé breton, installé dans le pays à partir de la signature du concordat en 1860 (Deslisle 2003 : 83-98). On mesure le renversement idéologique provoqué par le développement des études ethnographiques, à partir des premières années $\mathrm{du} \mathrm{xx}^{\mathrm{e}}$ siècle, et le procès de valorisation du vodou qui l'accompagne. La nouvelle conjoncture, en dépit de ses limites, des résistances et des conflits qu'elle provoque (cf. Ramsey 2002 et infra, pp. 165-179) favorise l'adoption, dans le domaine des beaux-arts, de la thématique vodou qui deviendra centrale avec l'avènement de l'art naif. Et, bien plus, le vodou, en tant que tel, sera posé comme étant au fondement ou comme condition indissociable de l'haïtianité artistique.

\section{À la recherche de l'« authenticité totale »}

La peinture naïve peut être comprise comme « une tentative pour dépasser l'opposition du même et de l'autre ", pour abolir la dichotomie barbare / civilisé (Hurbon 1988: 5). C'est précisément dans le jeu de cette opposition que surgit le genre naïf.

En Haïti, tout commence par une incidence esthétique. Le Centre d'art, créé par l'artiste états-unien Dewitt Peters en 1944, accueille en son sein les principaux artistes issus de la mouvance indigène et s'oriente selon leur credo esthétique. Celui-ci est très vite ébranlé par une rencontre fortuite : José Gómez Sicre, critique d'art cubain, est à Port-au-Prince, pour présenter une exposition d'œuvres d'artistes de son pays, en janvier-février 1945. Il découvre dans les réserves du Centre une peinture envoyée aux dirigeants de l'établissement par un certain Philomé Obin qui peignait depuis quelque temps. La toile, Visite du Président F. D. Roosevelt au Cap-Haïtien le 5 juillet 1934, avait été acquise mais, parce que considérée comme l'œuvre d'un apprenti artiste, elle avait été placée dans les réserves. Sicre, associant cette œuvre à celles d'artistes du courant d'art naïf déjà constitué en Europe et en Amérique, fait valoir que Philomé Obin pratique une forme d'art spécifique, digne d'être appréciée. En d'autres termes, il affirme qu'il y a de l'art là où le credo esthétique en vigueur au Centre ne permettait pas qu'il soit reconnu. $\mathrm{Ce}$ jugement ontologique, à caractère valorisant ("ceci est de l'art»), énoncé dans un contexte favorable ${ }^{11}$ a rendu possible l'avènement de l'art naïf en Haïti (cf. Célius 2001, 2004). Cette appréciation de Sicre est suivie d'effets. Le Centre, à la suite de l'exposition 
des peintres de Cuba à Port-au-Prince, devait présenter une exposition à La Havane, où dirigeants et artistes commencèrent à se rétracter estimant que le niveau des artistes haïtiens était nettement en deçà de celui des Cubains. Sicre propose alors d'exposer les œuvres de Philomé Obin et des artistes qui lui sont apparentés, ou perçus comme tels. L'exposition se tient en avril 1945, inaugurant ainsi publiquement l'aventure de la peinture naïve d'Haïti. Ensuite les expositions se multiplièrent, bénéficiant de comptes rendus élogieux dans la presse internationale. Mais il a fallu attendre la fin de 1946 pour que le directeur du Centre, Dewitt Peters, se décide enfin à promouvoir en priorité l'art naïf, ce qu'il confirme dans un article paru dans Harper's Bazaar en janvier 1947 (Peters 1947). En 1951, l'art naïf triomphe en Haïti avec l'inauguration des décors muraux de la cathédrale épiscopale de Port-au-Prince (Fig. 7).

Il importe toutefois de comprendre le fondement conceptuel du jugement émis par Sicre. L'institution du courant d'art naïf résulte de la valorisation, par des artistes européens du début $d u \mathrm{xx}^{\mathrm{e}}$ siècle, de pratiques de création perçues comme des formes d'expressions " premières », comme «l'enfance de l'art ». L'art naïf émane donc du primitivisme. Mais l'esthétique indigène des années 1920 et 1930 a, elle aussi, une dimension primitiviste. Cependant elle ne rompt pas avec le projet civilisationnel du XIX ${ }^{e}$ siècle. Elle se propose de la redéfinir en assumant ce qui avait été occulté, nié, refoulé : la part sauvage d'Haïti. Il s'agit de parvenir à un savant équilibre entre valeurs de civilisation et primitivité. L'entreprise prend, à bien des égards, l'allure d'une domestication du primitivisme où les formes d'expressions considérées comme primitives sont établies comme sources, matériaux bruts au service de l'Art véritable, d'un art haïtien à fonder. L'art naïf rompt l'équilibre visé, déjoue la domestication. Il surgit comme l'expression, impossible à endiguer, du fonds originel haïtien dans toute sa nudité. Des voix s'élèvent contre son institutionnalisation, réclament la formation artistique des nouveaux créateurs, d'autres envisagent de fonder ou de refonder le véritable art moderne haïtien en puisant à la source nourricière de l'art naïf. En vain ! Le courant se développe de manière autonome, se consolide, s'amplifie et submerge tous les autres genres existants. On n'est plus, comme dans les années 1930, au niveau d'un simple élargissement thématique; un nouveau courant s'impose. Le " peuple » n'est plus uniquement un réservoir de thèmes dignes d'être peints ; « il » - des hommes et des femmes qui en sont issus, bien sûr - peint lui-même. Dans une structure sociale fondée sur l'exclusion et la barbarisation des masses, un tel phénomène ébranle les valeurs établies. D’où les résistances, les rejets, les polémiques qu'il suscite. On mesure combien a dû être déterminant le poids du regard et du marché extérieurs.

L'art naïf disqualifie l'esthétique indigène et apparaît comme le seul étalon de l'haïtianité artistique. Son authenticité serait totale : un art produit par des hommes, les Haïtiens véritables, vierges de toute culture artistique, ayant conservé, en dépit de la colonisation, de l'esclavage et de la longue histoire de leur pays, les pratiques, les valeurs, les croyances de l'Afrique ancestrale. L'argument s'élabore très tôt : de fait, dès 1947. Il implique une réécriture de l'histoire du Centre d'art de Port-au-Prince, une version adaptée de l'apparition de l'art naïf et la mise en avant du vodou comme principe général d'explication. On saisit l'ampleur de ce travail de réélaboration à travers les publications d'auteurs ayant écrit pour accompagner les débuts du Centre d'art comme celles de Dewitt Peters ou de Pierre Mabille ${ }^{12}$. Le nouveau discours s'affirme à travers des comptes rendus d'expositions où seuls les artistes "populaires " sont retenus et où tout est expliqué par le vodou, même si sont présentées des œuvres d'artistes aux préoccupations 
différentes, aux styles distincts et traitant de thèmes variés ${ }^{13}$. Ce réaménagement se cristallise autour de la figure d'Hector Hyppolite. La légende qu'il a inventée (il aurait effectué des voyages le menant jusqu'en Afrique où il se serait initié, d'autre part, il ne travaillerait que sous la dictée des lwa) (Thoby-Marcelin \& Chenet 1948a, 1948b) est devenue l'énoncé explicatif de base. Or, Hyppolite doit son investiture à André Breton. Celui-ci séjourne en Haïti du 4 décembre 1945 au 17 ou 18 février 1946. En visite au Centre d'art, il fixe son choix sur Hyppolite et lui seul. Il achète quelques-unes de ses toiles ${ }^{14}$ qu'il présente à l'exposition internationale du surréalisme organisée en 1947, à la galerie Maeght à Paris ${ }^{15}$.

Philippe Thoby-Marcelin rencontre Hyppolite pour la première fois en juillet-août 1945 et Breton voit ses œuvres quelques mois plus tard. L'exposition de La Havane a déjà eu lieu, inaugurant le temps de l'art naïf en Haïti. Hyppolite ne reçoit pas pour autant un accueil chaleureux au Centre. Thoby-Marcelin rapporte les réticences manifestées à l'égard de ses premières peintures. D'ailleurs lui-même se montre encore réservé, en octobrenovembre 1945, sur la manière dont procède Hyppolite et sur les résultats de sa démarche. L'artiste, observe-t-il avec regret, « peint visiblement avec trop de hâte et ne travaille pas ses fonds" (Thoby-Marcelin 1945). Hyppolite reste donc disponible pour qu'une « seconde découverte " par Breton puisse se produire.

\section{Alfred Métraux, Hector Hyppolite en compagnie de Dewitt Peters, 1948}

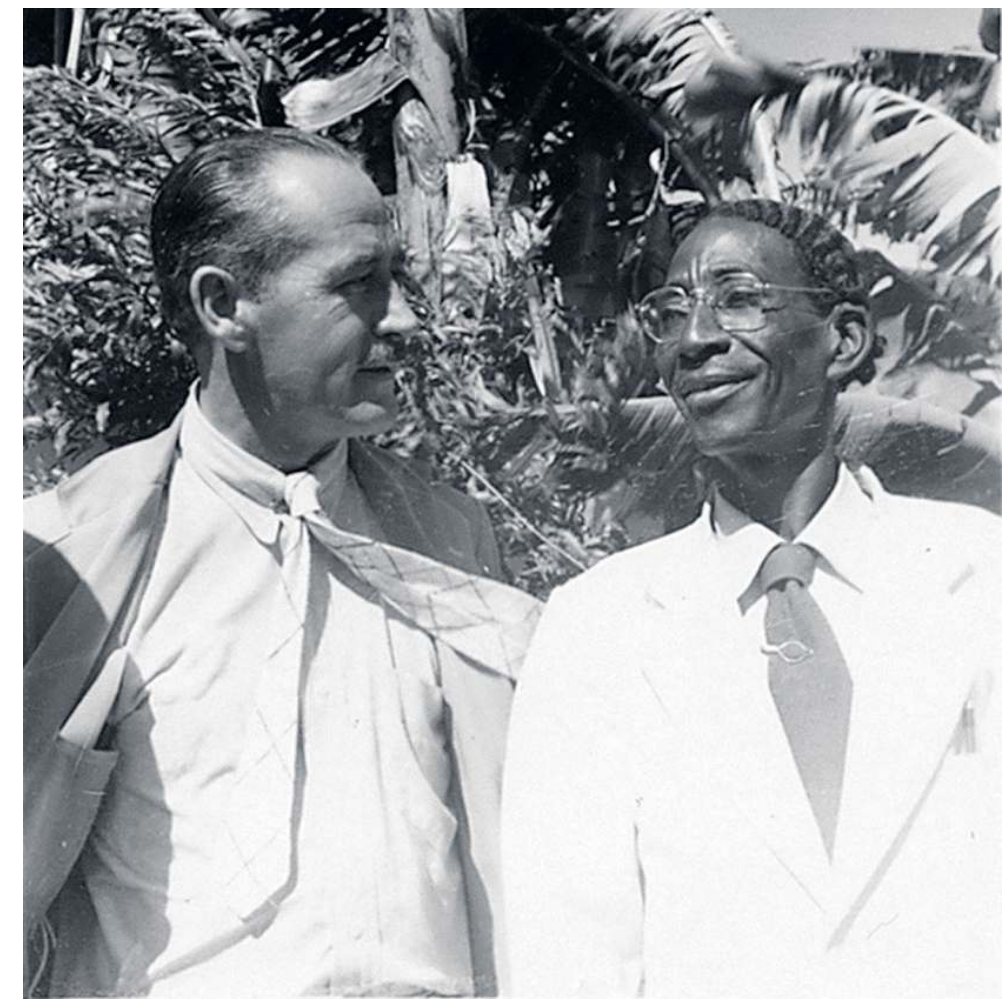

(c) musée du quai Branly, photo Alfred Métraux

Breton raconte que lors de sa visite au Centre, les œuvres d'Hyppolite « étaient les seules de nature à convaincre que celui qui les avait réalisées avait un message d'importance à faire parvenir, qu'il était en possession d'un secret » et " le secret c'est tout ». L'artiste est pourtant «dans l'ignorance de toutes les recettes de "composition" que se transmettent les artistes professionnels et qui tendent de plus en plus à faire dépendre la peinture des 
secrets de cuisine». Il réussit ses œuvres, atteignant "d'une manière spontanée, instinctive à l'équilibre ». Et, donnée fondamentale, ses peintures «étaient marquées du cachet de l'authenticité totale ». Son œuvre " peut être réputée pure de tout alliage ». Elle émane "d'un homme de moins de cinquante ans, noir, aux traits fins, du beau type guinéen ", en d'autres termes, un Africain pur sang dont l'œuvre " manifeste une foi sans limites dans les révélations et les pratiques de culte "vodou" en même temps qu'une aptitude exceptionnelle à se représenter concrètement les divinités qui y président ». De fait, ajoute-t-il, cette initiation, « Hector Hyppolite l'avait reçue au cours d'un séjour de sept ans au Dahomey ». En tout état de cause, « La peinture d'Hector Hyppolite apporte [... ] les premières représentations qui aient été fournies de divinités et scènes vodou. À ce titre seul, en tant que peinture religieuse primitive, elle présenterait déjà un intérêt considérable $»^{16}$. On reconnaît, dans ces phrases, un argumentaire primitiviste d'ailleurs bien identifiable dans le dispositif discursif bretonien (Breton 1965b [1941]). Mais l'essentiel est que par le geste et la parole de Breton, Hyppolite est devenu et est resté le " peintre du vodou " par excellence, le chef de file de la " peinture vodou " qui peignait en état de possession. Une figure de ce type de peintre est ainsi forgée, dont se serviront bien d'autres artistes.

Hyppolite a cherché à apporter des correctifs à sa légende en usant du double langage (ce que d'ailleurs feront après lui des peintres réputés travailler en état de possession, comme André Pierre ou Célestin Faustin). Rien n'y fait. Cela a pour conséquence d'occulter des aspects différents de son œuvre. Hyppolite n'a en effet pas peint que des sujets relatifs au vodou ${ }^{17}$. Cela ressort peu des commentaires consacrés à son œuvre. En outre, les commentateurs établissent rarement des relations entre ses tableaux et les décors peints (qui ont révélé son talent) des portes du petit bar de Montrouis (Fig. 9 et 10). Or la structure formelle de ses peintures de chevalet est, au moins en partie déjà là, dans ces décors, avec ce dessin libéré de toute rigueur géométrique, aux traits légers, aériens, que prolongent des touches picturales relâchées. Par ailleurs, Hyppolite a accompli un geste significatif, passé totalement inaperçu. Après sa " découverte ", alors qu'il est installé à Port-au-Prince, il signale sa cabane par une enseigne : «Ici station de peinture ». Tout le sens de cette indication ressort quand on la rapporte à une réponse qu'il a donnée à Rodman qui l'interrogeait sur son statut : il dit en effet avoir demandé la permission aux lwa de se consacrer désormais à son nouveau métier de peintre.

21 André Breton, en portant son choix sur Hyppolite parmi tant d'autres artistes et en le désignant comme peintre du vodou et comme le seul ayant fait œuvre authentique, indiquait qu'il ne saurait y avoir d'art vraiment haïtien s'il ne s'inscrivait dans ce rituel. Une base d'orientation était alors donnée au mouvement naïf naissant, un critère d'évaluation de l'« haïtianité » était formulé (Fig. 10). Selden Rodman (1948) adopte cette même perspective. Pour lui, l'avènement de l'art naïf en Haïti, signifie la renaissance des pratiques artistiques héritées de l'Afrique, qui jusque-là avaient été refoulées. À la suite de Breton, de Rodman, tout un courant discursif s'est développé qui explique l'«art haïtien », son authenticité, par le vodou. Ainsi, l'« haïtianité » est-elle rattachée au vodou, lui-même ramené à l'Afrique; ce qui a porté nombre de chercheurs à qualifier l'«art haïtien » de néoafricain - certains allant jusqu'à parler d'atavisme ou de mémoire raciale.

On voit donc comment et on comprend surtout pourquoi Hyppolite - qui n'a pas participé à l'exposition inaugurale de La Havane en avril 1945 - est devenu le héros fondateur, le chef de file du courant naïf, dépassant de loin en réputation Philomé Obin, celui dont une des œuvres avait tout déclenché. Peintre d'histoire, non vodouisant, évoquant son intérêt 
pour la perspective, il s'accommode mal non pas tant du primitivisme, fondement conceptuel de l'art naïf, que de la nouvelle version haïtianisée du primitivisme.

\section{L'école haïtienne d'ethnologie face à l'avènement de l'art naïf}

sporadiques de peinture et de sculpture [insuffisantes pour] caractériser une production artistique ». Certes il écrit du sculpteur Normil Charles qu'il «pétrit dans la glaise les rêves de gloire qui hantèrent jadis le cerveau de nos héroïques aïeux [...]. Mais une hirondelle ne fait pas le printemps... » (Price-Mars 1998 [1928] : 180). Ce constat d'un vide en matière de création plastique est pour le moins étrange, et il révisera d'ailleurs plus tard cette appréciation négative. Du reste une publication de 1926 d'Édouard Goldman, lui-même peintre, fait notamment état des œuvres conservées au Palais du Centenaire inauguré aux Gonaïves en 1904, des toiles du XIX ${ }^{e}$ siècle accrochées à la cathédrale coloniale de Port-au-Prince, et de ce fait ébranle ce diagnostic. Toujours est-il qu'il est repris au début des années 1930 par Savain et son entourage (Savain 1936, Sylva 1938), qui s'octroient ainsi le privilège de l'invention des beaux-arts en Haïti et de l'haïtianité dans le domaine. Le vide s'étendant au-delà des limites de ce champ, aucune forme de création plastique " populaire » n'est identifiée comme source potentielle d'inspiration, à l'instar de celles indiquées pour la musique, la danse et la littérature. L'haïtianité en matière plastique se limitera au niveau thématique, en recourant au modèle littéraire. D'ailleurs, insiste-t-on: «L'atelier de Savain devint assez vite le lieu de réunion de l'avant-garde littéraire de l'époque (le poète Émile Roumer en tête), qui l'emplissait de son exubérance, ouvrant au peintre des horizons nouveaux, lui enseignant l'audace " (Thoby-Marcelin 1956: 23). Savain lui-même publiera un roman, La Case de Damballah (1936- 1939), illustré de gravures (Fig. 11). Thoby-Marcelin remarque que dans le roman il expose « le drame quotidien de nos paysans et [retrouve] de la sorte, les situations étant les mêmes, le lyrisme naïf et la fraîcheur primitive de la Marchande d'accassan » (ibid:: 25). Nombre de ses œuvres picturales, comme Marché dans la montagne (1938), semblent avoir été inspirées de certains passages du roman.

Il est moins aisé d'établir une relation directe entre l'œuvre de Price-Mars, le discours des tenants de l'esthétique indigène et l'apparition de l'art naï. Sicre a énoncé son jugement sur l'œuvre d'Obin indépendamment et d'ailleurs contre les valeurs de l'esthétique indigène. Son cadre de référence, comme celui de Breton, se situait ailleurs. Au moins l'école haïtienne d'ethnologie était interpellée.

Quand se pose, en 1945-1947, la question de la promotion de l'art naïf, le processus d'institutionnalisation de cette école est déjà bien engagé, surtout que l'Institut et le Bureau d'ethnologie avaient été fondés en 1941. Ce nouveau type d'art soulève d'emblée 
bien des problèmes qui intéressent directement la nouvelle discipline, notamment ceux relatifs à l'identité et à l'authenticité, au religieux et au sacré, à la mémoire sociale et « raciale». On s'interroge sur la meilleure façon de le qualifier: populaire? naïf ? primitif? De surcroit, cet art accomplit, dans une certaine mesure, ce que le chef de file, Price-Mars appelle de ses vœux depuis les années 1910 : la promotion des gens du peuple, la reconnaissance de leurs potentialités et des valeurs dont ils sont porteurs. L'art naïf apporte de nouvelles données à l'étude des caractéristiques de la culture haitienne et de sa dynamique interne.

\section{Price-Mars, le folklore et la création plastique}

Pourtant, dans la bibliographie des œuvres de Price-Mars dont on dispose (Hoffmann s.d.) ne figure aucune étude spécifiquement consacrée aux langages plastiques d'Haïti en général et à l'art naïf en particulier si ce n'est un compte rendu du roman de Pétion Savain paru dans le numéro du 10 février 1940 de Haïti Journal. Il faut donc effectuer une recherche minutieuse des opinions qu'a formulées Price-Mars sur la création plastique dans son abondante production, notamment dans les "essais " sur «les arts», la littérature et la culture des années 1950.

Au début de ces années, à l'heure où triomphe l'art naï, Price-Mars parle de la diversité, de la relativité du beau et des manifestations artistiques, reprenant ainsi un thème de réflexion qu'il avait abordé dès 1907 dans sa conférence sur « L'esthétique dans les races » (2001 [1919]).

«Que la beauté soit multiforme et ne réside pas seulement dans l'expression immortelle qu'elle revêtit jadis sur les bords de la mer Egée dans la statuaire grecque et la métaphysique aristotélicienne, qu'elle se soit extériorisée aussi dans l'impressionnisme de l'art japonais, la richesse de détail de l'art hindou, le faste du coloris de la peinture chinoise, qu'elle se soit explicitée dans le réalisme émouvant et la stylisation de la sculpture nègre, c'est qu'en définitive la beauté ne doit pas être prisonnière d'une forme unique, standardisée, immobile, momifiée. La beauté peut et doit revêtir un idéal d'expression selon les peuples, les milieux et les époques en incarnant la puissance de la vie dans la plasticité de la matière en insufflant l'émotion dans la cadence du rythme, de la sonorité cristalline ou voilée $\mathrm{du}$ vocable, dans la souplesse harmonique du mouvement, dans la symétrie et l'ordonnance des détails. Peinture, sculpture, architecture, danse, poésie seront des expressions d'art aussi bien génériquement humaines que spécifiquement nationales ou indigènes » (Price-Mars $1951: 51$ ).

Qu'en est-il du cas précis d'Haïti ? Dans les années 1920, Price-Mars invitait les créateurs à s'inspirer du folklore pour fonder un art véritablement haïtien. Il s'adressait aux nombreux romanciers, aux musiciens dont «beaucoup d'ouvriers [étaient déjà] à la tâche ", mais pas aux plasticiens - il n'en voyait pas. Il tend par la suite à rectifier cet état des lieux. Il reconnaît qu'« entre 1850 et 1904, la floraison des artistes et des hommes de lettres s'épanouit en gerbes magnifiques dans tous les domaines. Musique, peinture, sculpture, littérature ont fait éclore des talents robustes et brillants » (Price-Mars 1959a : 93). Aux côtés d'un Démesvar Délorme, théoricien, d'un Oswald Durand, d'un Tertullien Guilbaud, Massillon Coicou, Georges Sylvain, Etzer Vilaire, littéraires, il retient les noms d'Edmond Laforesterie et de Normil Charles, sculpteurs, d'un Colbert Lochard, peintre ou d'Occide Jeanty, musicien. Cependant, c'est dans les années 1950 que la floraison s'est montrée plus intense. 
«Il n'est pas interdit d'associer à cette ferveur dont jouit l'art sous toutes ses formes, en ce moment, l'engouement qui a poussé le public depuis une vingtaine d'années à encourager la floraison des arts plastiques. Comme par enchantement, a paru, sous notre ciel, un essaim de peintres, de sculpteurs et d'architectes dont les tableaux, les marbres, les bronzes ont soulevé l'admiration générale et ont acquis la faveur des connaisseurs dans les expositions internationales en Europe et dans les Amériques » (Price-Mars 1959b : 70-71).

Price-Mars tente d'être plus précis dans un autre essai. « De toute cette activité, il résulte qu'entre 1915 et 1953, soit en trente-huit ans, notre littérature et nos arts se plièrent à une orientation nouvelle.»

Il poursuit :

«Pour la première fois apparut une floraison d'arts primitifs qui conquirent les lauriers des expositions internationales grâce à la diligente amitié de M. Dewitt Peters. Pour la première fois des chœurs sous la direction de M. Michel Déjean, participèrent avec succès à des festivals internationaux, au-delà des mers, en faisant valoir des airs de notre folklore et de nos traditions populaires. Pour la première fois, une Catherine Dunham qui vint chez nous s'instruire et s'approvisionner des richesses de notre folklore s'appropria la technique de nos danses populaires et alla sur les scènes américaines et européennes les faire applaudir en un succès grandissant. Pour la première fois des troupes folkloriques sous la direction de Madame Fusman Mathon ou d'autres personnalités après avoir moissonné des triomphes locaux vont faire apprécier nos virtuosités artistiques à l'étranger. Pour la première fois, des musiciens tels que Ludovic Lamothe, Justin Elie, Carmen Brouard, sans renoncer à la norme classique de leur éducation artistique, s'inspireront des motifs de nos paysages ou de nos mœurs pour écrire "Sous la tonnelle", "Danse tropicale" ou "La Mer Frappée" » (Price-Mars 1959a: 99).

Price-Mars enregistre avec satisfaction le triomphe de ses recommandations: pour la première fois, les arts et la littérature prennent une orientation nouvelle en tirant parti du folklore. Et « la floraison des arts primitifs » participe de cet accomplissement. Mais ces « arts primitifs » équivalent-ils aux musiques, chants, danses... " populaires » ou à celles qui s'en inspirent? Le terme "populaire » situe explicitement les pratiques qu'il associe au champ du folklore, tel que celui-ci est défini dans Ainsi parla l'oncle. Une relation d'équivalence avec celui de primitif supposerait une conception désormais élargie de ce champ: Price-Mars qui y en excluait les "arts populaires » aurait alors identifié les formes de création plastique de notre «fonds de traditions ». De ce point de vue, le rôle qu'il attribue à Dewitt Peters consisterait en la promotion internationale d'un type de création jusque-là méconnue et qui fleurit désormais "comme par enchantement». Dans cette perspective, les "arts primitifs" ne sauraient avoir les mêmes caractéristiques et le même statut que les créations inspirées du folklore. À l'évidence, Price-Mars ne perçoit pas ces implications. Et ce qualificatif de primitif, dans quel sens l'entend-il ? Dans Ainsi parla l'oncle il l'emploie pour caractériser les cultures africaines. Il parle de «foi primitive» (Price-Mars 1998 [1928] : 106), de "pensée du primitif » (ibid.: 88), "de la vie nègre en son mode primitif » (ibid:: 114). Pour lui, «L'animisme nègre n'est autre chose qu'une religion de primitifs» (ibid.: 84). Et la création plastique des nègres ? La « sculpture nègre » est réaliste et stylisée. Puisque nous héritons de "lourds mystères de l'Afrique lointaine ", c'est sans doute de là que nous est venu «le réalisme [de notre] culture indigène" (Price-Mars 1951: 51). Reste à savoir comment articuler « réalisme culturel » et « peinture primitive ». En admettant peut-être le « réalisme » des « arts primitifs », y compris ceux qui fleurissent en Haïti, lesquels n'en sont pas moins d'inspiration africaine ${ }^{18}$. 
33 Price-Mars aborde le phénomène de l'art naïf en reprenant des éléments du discours commun, sans chercher à les intégrer de manière cohérente dans son propre dispositif discursif. Il n'entreprend aucune réflexion spécifique, notamment sur les notions employées pour qualifier cet art. Dans l'ensemble, il s'est contenté d'émettre des généralités, nous laissant le soin de conjecturer sur les imprécisions et les ambiguïtés qu'elles recèlent. Pourtant il disposait, depuis Ainsi parla l'oncle, d'un ensemble d'indices qui indiquaient des pistes d'enquêtes et auraient pu susciter des questionnements sur les pratiques antérieures de créations "populaires", sur les référents plastiques dont pouvait disposer un artiste d'origine paysanne, sur le vodou comme fondement de toute activité artistique dans le pays, et auraient pu être exploitées pour expliquer le surgissement de l'art naif. Tout d'abord, les «observances", les «croyances », les « cérémonies » qu'il se proposait de décrire sont généralement associées à des formes de production plastique. Pensons aux vèvè, dessins rituels du vodou, aux drapo, aux fers rituels ou encore aux décorations murales des ounfó. Il reproduit, dans Ainsi parla l'oncle, une photo de la collection du Dr Arthur Holly, montrant des «dessins cabalistiques » du vodou, les vèvè, qu'il se contente d'évoquer d'après la description d'une cérémonie tirée de Mimola, roman d'Antoine Innocent. À la même époque, l'attitude d'un William Seabrook (1929) est bien différente : il prend le temps de décrire le dessin rituel dont il lui a été donné d'observer l'exécution. Des manifestations plastiques s'imposent à PriceMars jusque dans sa relation d'une histoire d'amour paysan où il décrit la tenue portée par Ti Jean Pierre-Jean le jour de sa rencontre avec Dorismène.

« Il [Ti Jean] mit son plus neuf pantalon, endossa sa blouse de cotonnade bleue, à boutons de corozo doré, celle où l'artiste avait fait courir en dessins naïfs les points les plus fantaisistes d'une aiguille experte ; sapattes $^{19}$ de latanier enluminé de motifs à l'aniline, posées élégamment en bandoulière, Ti Jean va parler d'amour » (PriceMars 1998 [1928]: 192).

Ces faits sont suffisamment significatifs aux yeux de Price-Mars pour être rapportés. Tout aussi significatif est l'usage, dans les demandes en mariage, des papiers à lettre somptueusement décorés. L'auteur qui insiste sur cette pratique, relevée par la suite en d'autres endroits du pays par d'autres chercheurs ${ }^{20}$, reproduit un fac-similé de la lettre de Ti Jean (Fig. 14) (Price-Mars 1998 [1928] : 196-198). D'autres indices s'offraient encore à lui, comme les chromolithographies des saints catholiques en usage dans le vodou. Ces pistes n'ont pas été exploitées; elles sont pourtant fondamentales. Il nous suffit d'en donner un exemple : la circulation des images dans toutes les couches de la société depuis la période coloniale offre une des clés de compréhension de l'explosion picturale survenue à partir des années 1940.

Price-Mars (1953 : 73) avouera, dans une de ses conférences, que parler d'arts et de littérature ne lui sied que fort malaisément. Il dira plus explicitement son manque de familiarité avec la peinture d'Haïti.

«En 1958, à l'issue d'une communication sur la peinture haïtienne que nous avions faite à la SNAD [Société nationale d'art dramatique], sous le patronage du Dr PriceMars, rapporte Michel-Philippe Lerebours, nous avons demandé à ce dernier, au cours d'un entretien, de nous préciser ce "quelque chose de plus grand, de plus vrai" [qu'il faudrait à nos productions artistiques] ${ }^{21}$. Il hésita, réfléchit assez longtemps et puis nous répondit: "Les peintres primitifs pourraient peut-être mieux le dire que moi. Je pense qu'ils l'ont trouvé sans le chercher. Dommage que je ne sois pas très familier avec la peinture haïtienne". " (Lerebours 1989, I : 211, n. 47). 
insistance à parler d'arts nous invite à ne pas nous en tenir à cette justification ${ }^{22}$ Tout en s'excusant de parler littérature, c'est en fait à la littérature que pense Price-Mars lorsqu'il place d'emblée l'art au cœur de son projet ethnologique. En effet, dans Ainsi parla l'oncle, il se préoccupe de savoir si la société haïtienne dispose « ... d'un fonds de traditions orales, de légendes, de contes, de chansons, de devinettes, de coutumes, d'observances, de cérémonies et de croyances qui lui sont propres ou qu'elle s'est assimilée de façon à leur donner son empreinte personnelle, et si tant est que ce folklore existe, quelle en est la valeur au double point de vue littéraire et scientifique?» (Price-Mars 1998 [1928] : 5). De plus, il se demande «quel parti l'art et la littérature ont-ils tiré de [ce] folklore?» Il enchaîne : «Et d'abord y a-t-il un art haïtien, une littérature haïtienne ? (ibid.: 173) C'est dans ce contexte qu'il dresse le constat d'un vide en matière de création plastique.

La prééminence est accordée à la littérature et la délimitation du champ du folklore exclut la culture matérielle - ce qui est conforme à la conception du folklore la plus couramment admise dans les années 1910 et 1920 (Van Gennep 1943, I : 6-11, 19-42). La relation privilégiée avec la littérature est ainsi toute trouvée. Et elle est, à bien des égards, parfaitement justifiée aux yeux de Price-Mars. Lui-même a des aspirations littéraires comme en témoignent ses nouvelles et ses méditations lyriques (cf. "Son idéal », 1900 ; «Voyageuse », 1905, «Le Mufle», 1908; «Les Corbeaux », 1912, "Les Victoires mutilées », 1913...). Témoin du mouvement littéraire du début du siècle, il y cherche sa voie en s'exerçant aussi à la critique littéraire et à la réflexion sur l'esthétique. Sa conférence sur «L'esthétique dans les races » reprend un thème récurrent tout le long du $\mathrm{XIX}^{\mathrm{e}}$ siècle tout en étant en phase avec les discussions déjà amorcées sur la problématique de l'haïtianité. On cherche en effet à caractériser une préoccupation de plus en plus affirmée en parlant, dès 1905, des « Haïtianides », d'« haïtianités » (Marty 2000 : 74). Un roman illustrant cette démarche, Mimola (1906) d'Antoine Innocent fournira à Price-Mars matière ethnographique; il y puisera pour Ainsi parla l'oncle des descriptions de cérémonies vodou (Price-Mars 1998 [1928] : 138-143). D’ailleurs, en 1949, il consacrera «Antoine Innocent ethnographe» (Price-Mars 1953). Il faut ajouter que le domaine littéraire est alors le lieu d'expression le plus en vue de la créativité, le plus valorisé dans le pays (et, de ce fait, une des principales portes d'entrée dans le monde intellectuel). Ce poids de la littérature, lié à une définition traditionnelle du folklore, empêchait PriceMars de percevoir une quelconque forme de création plastique qui serait constitutive de « notre fonds de traditions » et, subséquemment, la possibilité pour les artistes plasticiens qu'il identifie, aussi peu nombreux soient-ils, d'en «tirer parti». Les indices dont il disposait ne prenaient pas sens pour lui. Pourtant, Paul Sébillot, sous l'autorité duquel il se plaçait pour définir le folklore, peintre lui-même, s'intéressait aux « arts populaires » ${ }^{23}$, lesquels avaient acquis une incontestable visibilité dans les recherches folkloristes à l'époque où émerge l'art naïf en Haïti ! Décidément le bouleversement provoqué par l'irruption de l'art naïf n'a eu aucun effet sur les recherches de Price-Mars. Il ne l'a pas conduit à réviser sa conception initiale du folklore qui a largement orienté l'école haïtienne d'ethnologie.

Ses considérations sur l'esthétique telle qu'exprimée par des " races » différentes et la diversité des manifestations artistiques sont reprises et font même l'objet d'un enseignement ${ }^{24}$. Ses disciples, surtout deux d'entre eux en fournissent la preuve, adoptent comme lui un rapport distancié à la création plastique. Lorimer Denis et François Duvalier, dans un article de 1936, notent l'importance de la découverte des arts d'Afrique pour l'art moderne : Picasso, Derain, Matisse, Segonzac, Laurencin y ont puisé les valeurs 
capables de les amener à « retrouver les frontières effacées de l'art ingénu des primitifs ». "De même aussi dans la peinture encore à l'état embryonnaire chez nous, M. Pétion Savain, au dire de sa critique $M$. Anthony Lespès, s'est affranchi des normes occidentales pour assouplir son talent au contact des disciples du cubisme d'inspiration franchement nègre. » (Denis \& Duvalier 1968: 214). Cependant, quand il est question de la peinture naïve, quand se pose le problème de son rapport à l'Afrique, les auteurs se dispensent d'intervenir dans le débat. En 1952, l'un d'eux, François Duvalier, prononce une conférence sur " la culture populaire » : il se limite à la poésie, au chant et aux danses dans « l'esthétique vodouesque $»^{25}$. Mais il n'a pu s'empêcher d'évoquer les beaux-arts. Traitant de l'importance de la connaissance de la culture nationale, de la nécessité de « la conserver » et de « l'augmenter », le conférencier soutient que :

"Cette conservation de la culture confiée aux musées, aux archives et aux bibliothèques sera augmentée d'une façon insoupçonnée. Pour l'encouragement moral de notre culture, qui est la base spirituelle de notre Nation et la base du véritable sentiment populaire, nous disposerons de centres de diffusion des beauxarts, des sciences et des belles-lettres, de conférences, de radiodiffusions, de centres de recherches scientifiques, littéraires, historiques, philosophiques, idéologiques, et artistiques et nous aurons également des académies: l'Académie des sciences, des belles-lettres, des beaux-arts, de l'histoire et des langues, des croyances religieuses, de littérature populaire et des traditions familiales et régionales » (Duvalier 1968a, I : 275-276).

Aucune allusion n'est faite au Centre d'art créé en 1944 par Dewitt Peters, qui promeut l'art naï, ni au Foyer des arts plastiques qui venait d'être fondé en 1950 par des dissidents du Centre, ni encore au décor de la cathédrale épiscopale qui venait d'être inauguré en 1951 marquant le triomphe de l'art naïf en Haïti. En ce début des années 1950, où le monde de la création plastique acquiert une certaine vigueur et suscite débats et même polémique, le discours de l'ethnologue y est imper- méable tout en se risquant à esquisser un projet d'institutionnalisation du monde artistique. Comme sur une table rase. Comme s'il s'agissait de partir du vide « constaté » par Price-Mars en 1928. 


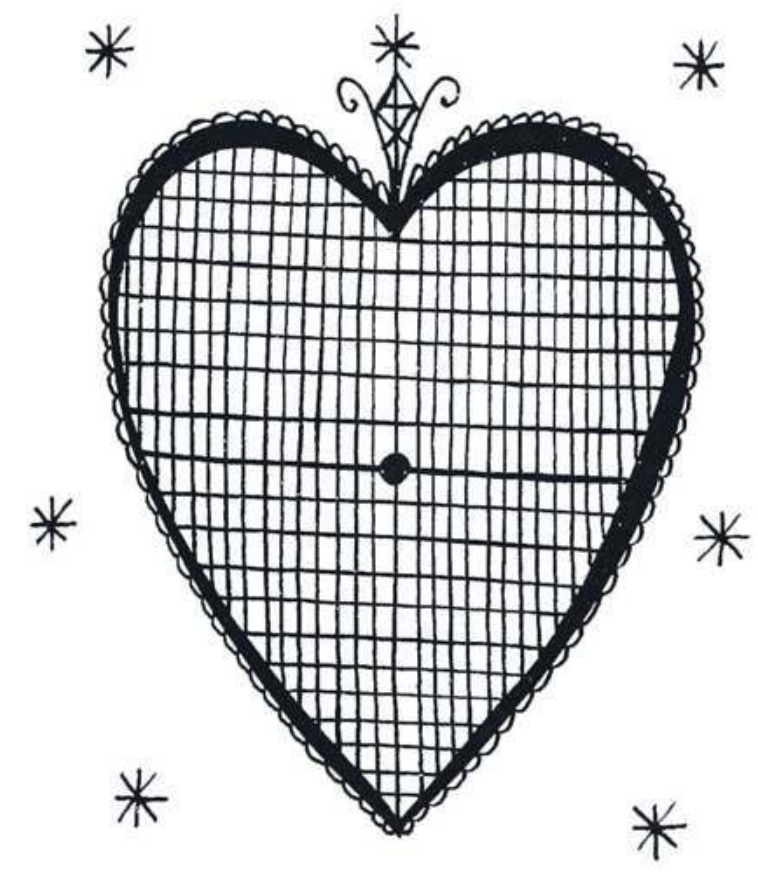

in Milo Rigaud, Ve-ve. Diagrammes rituels du voudou. New York, French and European Pub., 1974.

d'un vide artistique, admise en 1937 par Melville Herskovits - dont on sait qu'il a été influencé par Price-Mars (Yelvington 1999) -, est reprise à la fin des années 1950 par Milo Rigaud. Herskovits, à la recherche d'africanismes, observe qu'un ensemble de facteurs sociohistoriques a eu pour conséquence la destruction des traditions artistiques africaines en Haïti (Herskovits 1937 : 261-263). Il y voit les effets néfastes d'un conflit de traditions et soutient «... it is important to recognize that the suppression of these forms of the prevalent African tradition would seem to have lost to the Haitian an important outlet for the resolution on inner tensions caused by pent-up drives » (ibid.: 293). Milo Rigaud abonde dans le même sens, à partir de son approche cabalistique du vodou. André Breton lui avait adressé son questionnaire d'enquête sur L'Art magique, dans lequel il précisait :

«La catégorie d'œuvres d'art dont il s'agit comprenait à la fois celles que commande - ou sous-entend - une magie en exercice, soit bon nombre d'œuvres archaïques et la presque totalité de celle des "primitifs" (Afrique, Amérique, Océanie), celles qui, du Moyen Âge à nos jours, véhiculent la pensée dite "traditionnelle" et - sous la pression d'aujourd'hui - toutes celles dont le pouvoir sur nous excède ce qu'on pourrait attendre de leurs moyens décelables » (Breton 1991 [1957] : 259).

41

Breton, on l'a vu, percevait la peinture d'Hector Hyppolite comme une "peinture religieuse primitive » et soutenait que le statut de prêtre vodou du peintre présentait à ses yeux une garantie absolue de l'authenticité de son œuvre. "J'ignore ", ajoutait-il, «quelle part Hyppolite faisait respectivement à la magie et au culte proprement dit. Le plus probable est qu'il était de ceux qui, comme on dit en Haïti, "travaillaient des deux mains" (sont à la fois prêtre et magicien) $»^{26}$. 
le laisse comprendre :

«Pour avoir, en partie, "rejeté" (c'est-à-dire abandonné la volonté religieuse de magie qui leur est traditionnellement propre parce que vaudou), les Haïtiens ont perdu les "formes de l'art". Cette perte essentielle a créé la nécessité d'une "refonte de l'Histoire" d'Haïti où, seules les sources kabbalistiques qui ont valu à l'art universel les merveilles de la sculpture nègre, freinant "le déchaînement des forces obscures" qui conduisent sataniquement à l'imitation et à la fiction, redonneront divinement les pouvoirs de l'art de création» (Breton 1991 [1957]: 276).

Au cours de la campagne antisuperstitieuse menée au début des années 1940, on invitait les vodouisants à « rejeter » leurs pratiques, leurs objets, leurs croyances, d'où le nom de "campagne de rejeter». Quantité d'objets cultuels avaient été amassés et livrés en autodafé. La campagne, toutefois, a échoué ; elle n'a pas réussi à détruire le vodou. Mais c'est sans doute un rejet plus profond, global, que conçoit Rigaud. Ce que le statut conféré au vodou dans la société semble confirmer mais qu'infirment, les pratiques socioculturelles. D'où la nécessité de prendre en compte les conditions historiques de gestation et de structuration interne du vodou pour chercher à établir et à comprendre les types de productions plastiques qu'elles ont rendu possibles. Celles-ci paraissant insignifiantes en comparaison avec les "merveilles de la sculpture nègre", autant soutenir leur inexistence. Pourtant Milo Rigaud (1974) se penchera sur les vèvè, ce corpus graphique des langages plastiques vodou, mais sa critique radicale s'étend bien au-delà du vodou, et pour lui aucune forme d'« art de création » ne s'est développée en Haïti (Fig. 15a et 15b). Les quelques manifestations plastiques qu'on pourrait relever ça et là seraient de l'ordre de «l'imitation » et de... « la fiction », y compris l'art naif, qui pour d'autres, un Morisseau-Leroy, pour ne parler que de lui, aurait rompu avec une tradition d'art d'«imitation" (Morisseau-Leroy 1955b: 1). Rigaud rejette aussi dans le même mouvement la thèse selon laquelle l'art naif serait un art néo-africain ou encore un art magique.

\section{La voie de la culture matérielle}

La campagne antisuperstitieuse avait révélé au grand au jour la plastique vodou. Alfred Métraux explique (1989: 13) :

« C'est à la Croix-des-Bouquets, près de Port-au-Prince, que j'eus la révélation de la vigueur avec laquelle les cultes africains avaient proliféré en Haïti: l'énorme pyramide des tambours et d"'objets superstitieux" qui se dressait dans la cour du presbytère, attendant le jour fixé pour un autodafé solennel, en était le symbole. Je plaidai en faveur de quelques pièces qui, pour des raisons esthétiques ou scientifiques, auraient mérité d'être épargnées. En vain, le curé m'expliqua que l'honneur d'Haïti était en jeu et que tout devait être détruit. »

Métraux envisage alors d'étudier le vodou avant sa totale disparition. Et de ses conversations avec Jacques Roumain naît l'idée de créer un Bureau d'ethnologie chargé d'en sauvegarder le souvenir. "Quand je revins en Haïti, en 1944 », écrit-il, « le Bureau d'ethnologie, fondé par Jacques Roumain, avait sauvé des flammes d'importantes collections et entrepris diverses enquêtes sur des aspects peu connus du vaudou $»^{27}$.

Le Bureau est donc fondé sur une tout autre base que celle de l'orientation initiale donnée à l'école haïtienne d'ethnologie par Price-Mars (cf. Doucet, infra pp. 109-125). Jacques Roumain, son fondateur, doit sa vocation d'ethnologue à Ainsi parla l'oncle, selon plusieurs 
auteurs, mais il a été à une autre école, celle de Paul Rivet au musée de l'Homme à Paris. Et quelles que soient les limites de sa formation et de son œuvre scientifique, sa démarche diffère de celle de Price-Mars par la place qu'y occupe la culture matérielle ${ }^{28}$. Il en est de même de tous ceux qui constituent le noyau initial de cette nouvelle tendance, Louis Maximilien, Kurt Fisher, Edmond Mangonès, Rémy Bastien, mais si tous s'intéressent aux objets cultuels il ne s'agit pas des mêmes artefacts. En effet, des recherches archéologiques avaient été amorcées malgré l'absence de tout cadre institutionnel local (Aubourg 1951) et avaient donné lieu à une exposition d'objets taïnos organisée à Port-auPrince en 1941. Le catalogue, L'Art précolombien d'Haïti, avait été préparé par Louis Maximilien et Edmond Mangonès (1941). Le titre de cette publication suffit à suggérer que ce type de chercheurs était plus disposé à se pencher sur les autres formes de production plastique. Quant à A. R. Bastien, il publie en 1944 une importante étude sur des tableaux du XIX ${ }^{\mathrm{e}}$ siècle accrochés à l'ancienne cathédrale de Port-au-Prince (Bastien 1944b). Edmond Mangonès (1943a, 1943b) étend son champ de recherches à la numismatique. Louis Maximilien (1943) s'intéresse à la plastique "populaire " sacrée et profane, liée à l'héritage précolombien.

47 C'est dans cette perspective qu'il aborde le vodou dans son ouvrage Le Vodou haïtien. Rite radas-canzo (Maximilien [1945]) où son intérêt pour les objets cultuels et les manifestations plastiques est clairement exprimé. Le livre comporte un grand nombre d'illustrations (dessins et photos) qui servent de supports à la description et à l'analyse. Les décorations extérieures et intérieures des ounfô n'ont pas échappé à l'auteur. Il consacre tout un chapitre aux vèvè (ibid.: 41-51) qui sont d'ailleurs évoqués tout au long de l'étude. À part les photos montrant ces dessins en situation, un corpus a été établi de vingt-quatre vèvè redessinés et présentés, pour vingt-deux d'entre eux, avec leurs formules d'invocation, les deux autres étant des vèvè combinés (ceux des tambours et du oungan, ceux des pots rituels dénommés zen). Pour Maximilien, ce sont des "éléments essentiels aux rites cérémoniels", si bien qu'il convient de les analyser avant même d'entreprendre la description des cérémonies. Il définit ce qu'est un vèvè, indique les lieux et les moments de son exécution, les ingrédients et la technique utilisés pour le réaliser.

« [La] farine est prise par petite quantité entre le pouce et l'index, et on la laisse tomber à la manière d'un sablier. Le houngan, en faisant mouvoir la main, obtient les lignes de son dessin. Les motifs sont exécutés avec une habileté égale à celle d'un artiste travaillant au crayon sur du papier ou mieux, à la craie, au tableau noir. Au cours des cérémonies, ces vêvers [sic] constituent de véritables manifestations d'art. Ils supposent un sens développé de la perspective. Aussi, les vodouisants, accordent-ils une grande importance au fait de savoir "tirer la farine" » (ibid.: 41).

Maximilien s'interroge sur l'origine des vèvè. S'il soutient la thèse d'une provenance précolombienne, il y voit l'expression des vestiges de la culture totémique africaine et surtout les influences de la magie européenne, confirmées par des rapprochements iconographiques. Car certains motifs s'apparentent à ceux relevés sur les pentacles du «Clavicule de Salomon » ou du grimoire du Pape Honorius III et on y retrouve des cercles magiques ou encore "Le Triangle des Pactes ». L'auteur établit un rapprochement tout à fait convaincant entre le vèvè d'Èzili et l'effigie du Sacré-Cœur dessinée par sainte Marguerite Marie en 1685, tout en démontrant que le motif est déjà présent dans le livre de cabale alchimique de l'Agneau intitulé Harmonie mystique, ou accord des philosophes chymiques, daté de 1636. L'ouvrage comporte en effet deux "hiéroglyphes alchimiques " qui proviennent de deux monuments antérieurs au $\mathrm{xvI}^{\mathrm{e}}$ siècle, et qui sont, selon Maximilien, une « représentation anticipée du Sacré-Cœur ». 

(Saint-Louis $2000: 18-20$ ), a été très tôt contestée ${ }^{29}$. Mais Maximilien a ouvert en même temps la voie d'une approche iconographique qui reste encore à explorer de façon approfondie.

50 famille spirituelle des peintres de "l'instinct et du cœur" rencontrés sous tous les cieux et à tous les âges", mais dont la singularité tient à ce que «...ses compositions et ses rythmes » lui « viennent directement du vodou». Hyppolite hérite des richesses de «la religion populaire haïtienne " dont les rites sont "africains" tout en étant nourris d'« apports alchimiques, magiques et maçonniques » (Maximilien $1947: 25,29$ ), et il initie une «nouvelle école de peinture à caractère ésotérique ». La parenté de cette proposition avec le discours tenu par André Breton est évidente. Celui-ci connaissait les travaux de Maximilien, les cite en plusieurs endroits, reprenant notamment ses considérations sur les différents apports constitutifs du vodou et sa thèse sur l'origine précolombienne des vèvè.

51 Le courant d'études sur la culture matérielle ne s'est malheureusement pas engagé plus à fond dans la recherche sur l'art naïf. Il est vrai que cette tendance elle-même a eu du mal à prospérer. Dans une analyse de la production scientifique du Bureau portant sur 116 articles recueillis dans 37 numéros de son Bulletin parus de 1943 à 1986, Raymonde Giordani (1987) observe que soixante-deux articles, soit $53 \%$, traitent de la tradition religieuse; vingt-cinq d'entre eux étudient spécifiquement le vodou dans ses divers aspects et les trente-sept autres en traitent d'une manière ou d'une autre. Dans cet ensemble, la plastique vodou proprement dite n'a pas bénéficié d'une très grande attention. Sous une autre rubrique, Giordani dénombre vingt-cinq articles consacrés à l'archéologie et à l'histoire précolombiennes, dont onze, soit $40 \%$, écrits par des chercheurs étrangers. Sur la totalité des articles répertoriés, et même en les complétant à l'aide du répertoire établi en 1992 par Arnold Dormilus (1994), on ne relève aucun article sur l'art naïf et on en compte seulement deux consacrés aux «arts populaires »: « La vannerie haïtienne : généralités et particularités », «La poterie haïtienne : généralités et particularités ", publiés respectivement en 1969 et en 1974 par Jacques Oriol. Giordani souligne l'absence d'études sur nombre de pratiques artisanales pourtant importantes dans la vie de la collectivité. Certes les études recensées témoignent d'une grande diversité thématique, mais la préoccupation centrale reste la tradition religieuse. «Cependant, estime Giordani, ce souci se traduit trop souvent par des inventaires et analyses du champ symbolique, alors que le champ de l'utilitaire reste inconnu. » Il faut y voir, en fin de compte, le triomphe, au sein du Bureau dédié à l'étude de la culture matérielle, de la voie initiale définie par Price-Mars.

Si la production scientifique de l'Institut, devenu Faculté d'ethnologie, semble présenter une plus grande variété d'études, force est de constater que là aussi l'art naïf reste singulièrement en dehors des préoccupations. Le répertoire des mémoires de fin d'études pour la période allant de 1959 à 1970 en témoigne ${ }^{30}$. Il en est de même des travaux de folklore de 2e année du cursus, si l'on s'en tient à la sélection proposée par Max Benoît pour la période allant de 1969 à $1978^{31}$. En cette année 1978, Jean-Baptiste Romain, alors doyen de la Faculté, publie Africanismes haïtiens. Compilations et notes, ouvrage qui constitue à la fois le $\mathrm{n}^{\circ} 31$ de la Revue de la Faculté et le $\mathrm{n}^{\circ} 6$ du Bulletin de l'Académie des sciences humaines et sociales d'Haïti. Romain (1978: 9) entend, à partir de la méthode proposée par 
Herskovits, établir une première synthèse des données sur les survivances africaines en Haïti.

Pour Herskovits, la culture peut être étudiée comme une série de variables à la fois interreliées et indépendantes qu'il dénomme " aspects». C'est par ces «aspects » qu'est donné le degré de survivance. Cela tient à la variabilité des éléments culturels dans leur forme et dans leur capacité de changement dans une situation historique donnée. Ainsi les degrés de rétention sont fonction des aspects de la culture. Il y a par exemple beaucoup plus d'africanismes dans la religion que dans la vie économique, davantage dans les classes sociales inférieures que dans les classes plus favorisées. Herskovits aboutit à une échelle d'intensité des africanismes dans le Nouveau Monde où seul le plus grand degré de rétention est retenu pour chaque groupe. L'échelle comprend six degrés allant du purement africain (a) à l'absence d'indication (?) en passant par très africain (b), assez africain (c), un peu africain (d) et traces de coutumes africaines ou néant (e). Dix « aspects » sont retenus : technologie, vie économique, organisation sociale, institutions, religion, magie, art, folklore, musique, langue (Herskovits 1967 : 305-307). Selon le tableau qui en résulte, la religion, le folklore et la musique sont "purement africains" dans les campagnes haïtiennes, tandis que dans les villes, seuls le folklore et la musique le sont. Et l'intensité est variable pour les autres aspects. "L'art» par exemple est «un peu africain » dans les campagnes et ne garde que des «traces de coutumes africaines ou néant » dans les villes.

C'est cette approche que Romain entend reprendre en vue de sa synthèse. Il précise qu'il s'agit pour lui «de vérifier si les manifestations culturelles d'inspiration africaine, indiquées dans [le tableau établi par Herskovits] ${ }^{32}$, répondent à des réalités dans la société haïtienne d'aujourd'hui ; si oui, de compléter ce tableau au besoin sans s'astreindre à prendre en compte l'élément intensité en rapport avec la rétention des dites manifestations» (Romain 1978 : 8). L'auteur conclut que le tableau d'Herskovits, légèrement modifié et complété se vérifie encore et surtout dans la paysannerie et qu'« Haïti se révèle ainsi un laboratoire d'expérimentation de ces survivances » (ibid.: 98). En ce qui concerne "l'art» et en se référant à Marcel Griaule (1947), il part d'une caractéristique définie de "l'art africain», de son «esprit utilitaire [...] religieusement parlant ", qu'il retrouve « dans maintes démarches des masses paysannes haïtiennes, sous le rapport de l'architecture, de la sculpture, de la peinture, des arts du dessin, par exemple» (ibid: 26-27). Il retient le lakou, prototype de "l'habitation paysanne traditionnelle » en matière architecturale, deux objets cultuels, l'asen ${ }^{33}$ et le pakèt ${ }^{34}$, comme exemples de sculpture et les vèvè pour les arts du dessin. S'agissant de la peinture, l'auteur se contente de parler de la symbolique des couleurs. En fin de compte, si cette rubrique "art» a le mérite d'exister, elle est loin d'être une véritable synthèse des différentes études menées jusque-là et l'art naïf n'est pas traité en tant que tel, même si l'africanité de cet art est en débat depuis son irruption.

L'avènement de l'école haïtienne d'ethnologie et celui de l'art naïf sont deux événements distincts, qui participent toutefois d'un même paradigme. À travers l'un et l'autre s'affirme l'existence de formes, de pratiques, de valeurs considérées comme premières, primitives, qu'il convient d'accepter et de promouvoir comme telles. Ils s'inscrivent donc dans le primitivisme et en cela subvertissent l'échelle des valeurs sociales établies, fondées sur une conception de la "Civilisation». En raison de ce partage d'un même univers paradigmatique, le procès de valorisation du vodou, et de la " culture populaire " d'une manière générale, engagé par Price-Mars a pu paraître comme l'événement qui a 
engendré l'art naïf. La différence entre les deux phénomènes devenait d'autant plus imperceptible que la démarche ethnologique offrait un cadre général de justification et une explication globale de l'art naïf. Ce qui, en retour, ne manquait pas d'influer sur la production artistique elle-même. Les conditions d'une exploration systématique de la thématique vodou étaient alors créées, ouvrant de nouveaux espaces imaginaires à la création plastique. Mais l'avènement de l'art naiff est un phénomène de grande ampleur aux implications multiples. Il institue un mode de représentation en rupture avec celui qui était jusque-là légitimé en entraînant la promotion d'hommes et de femmes issus d'une catégorie sociale alors déconsidérée. Il provoque une densification, une massification même, de la production plastique accompagnée d'une reconfiguration du marché de l'art sur le plan interne. Et c'est dans cette dynamique que s'est constitué un nouveau lieu de réflexion dans l'histoire intellectuelle du pays, celui du discours sur la création plastique. Certes, des écrits sur «l'art » ont existé auparavant, mais désormais émerge un véritable espace discursif, c'est-à-dire un espace créé autour d'une série de questions posées, traitées, donnant ainsi lieu à une masse discursive plus ou moins importante et clairement identifiable; traduisant des enjeux spécifiques et ayant des effets repérables. On voit bien que le phénomène de l'art naïf ne peut pas être confondu avec ce procès de folklorisation de «la culture populaire», dénommée "mouvement folklorique " en Haïti (Ramsey 2002). Évidemment il n'y a pas échappé, mais sa dynamique propre ne saurait être occultée pour autant.

$\mathrm{Au}$ départ de tout cela, il y a l'énonciation d'un jugement esthétique fondé sur le renversement opéré dans la relation d'opposition primitivité / civilisation. Car le primitivisme n'est pas autre chose. Il consiste plus précisément en un relèvement de la fonction négative jadis conférée au "primitif » par rapport au «civilisé ». C'est dans le mode d'appropriation de ce renversement et dans ses effets que réside la différence entre l'avènement conjoint de l'école haïtienne d'ethnologie et de l'art naïf. Le primitivisme qui sous-tend l'injonction de Price-Mars, s'inspirer du folklore pour créer un art proprement haitien, était encore trop médiatisé par l'idéal civilisationnel pour être à même de libérer une parole, comme celle de Gómez Sicre, capable d'instaurer l'art naïf. Par contre, cette instauration une fois accomplie, on voudra transformer le nouveau genre en source d'inspiration, la source jusque-là manquante à laquelle puiser les substances d'un véritable art plastique haïtien. Philippe Thoby-Marcelin (1945) le recommande dès 1945; Max Pinchinat en élabore la doctrine à travers toute une série de publications ${ }^{35}$ et il s'est efforcé de l'illustrer par son œuvre.

C'est à ce niveau justement, celui de l'appréhension du phénomène naïf, des débats qu'il a suscités, donc de la constitution de l'espace du discours sur l'« art », que l'école haïtienne d'ethnologie joue un rôle essentiel. Elle n'inclut certes pas la création plastique dans son horizon d'exploration, mais elle occupe très vite la place centrale dans l'univers discursif - place qui revenait en quelque sorte à l'histoire au XIx ${ }^{\mathrm{e}}$ siècle - ; elle devient la formation discursive $^{36}$ qui informe toutes les autres en ce qu'elle redéfinit Haïti en tant que " communauté », non pas uniquement par son historicité, mais aussi et avant tout par ses composantes culturelles.

L'art naïf s'étant imposé, le discours ethnologique, qui définit ou redéfinit la culture et valorise la "culture populaire", aide à le penser. Devoir le penser sans rejeter l'expérience de la "modernité indigène », en prenant en compte toutes les controverses et les prises de position des artistes produisant un art non naïf, offrait au discours haïtien sur la création plastique une largeur de vue lui permettant d'élaborer une démarche 
différente de celle des courants discursifs étrangers (principalement états-unien avec Selden Rodman [1948, 1988] comme figure centrale, et français, avec André Breton, André Malraux [1976], Jean-Marie Drot [1974, 1988]). Ceux-ci s'en tiennent à une forme d'exclusivisme où seul l'art naïf compte, considéré comme la seule écriture picturale capable d'exprimer l'haïtianité, tandis que le courant haïtien en vient à adopter une démarche intégrative, cherchant à dégager une haïtianité artistique ouverte, à travers toutes formes de création plastique produites sur place ${ }^{37}$. Malgré tout, le courant haïtien se heurte à une série d'impasses. Surgi avec la problématique de l'haïtianité, ce courant aborde celle-ci à partir d'un discours ethnologique qui n'a pas su s'impliquer dans le débat, qui n'a apporté aucun éclaircissement conceptuel et n'a offert aucune approche méthodologique alternative. Aussi n'a-t-il pas pu se défaire des filets du primitivisme et même des ambiguïtés inhérentes à la version proposée par Price-Mars. Cela ressort nettement dans les considérations sur le vodou, qui serait source de toute création. Et on le perçoit bien dans la théorie du merveilleux de Jacques Stephen Alexis, principal effort d'élaboration d'une esthétique inspirée du tournant ethnologique. Alexis prône une concertation des intellectuels les plus clairvoyants de son temps pour rendre possible «l'essor d'un art conscient, rayonnant, véritablement au service de l'homme » (Alexis 1956a: 247). On y parviendra en apprenant à dissocier forme et contenu. Car il faudra s'accaparer des formes proposées par « la culture populaire ", garantes d'un art national, et y mettre un nouveau contenu, répondant au projet progressiste d'un humaniste nouveau. Alexis résume sa pensée en ces termes :

«Le vaudou est le reflet de notre infrastructure économique arriérée, d'une civilisation de la houe et de la machette dans un monde de tracteurs et de machines perfectionnées, le reflet du caractère semi-féodal sinon tribal de notre société. Le vaudou est un opium, et s'il faut recueillir soigneusement l'apport musical, choral, poétique, chorégraphique, verbal même, en un mot, toute la symbolique artistique d'un peuple qui a mis dans le vaudou tous les trésors que dans l'ignorance où on l'a laissé, il n'a pu mettre ailleurs. Il faut combattre ce respect fétichiste d'un certain folklorisme nationaliste et bélant [sic]. Il faut verser un autre contenu humain, universel, dynamique dans les merveilleux moules qui recèlent toujours les aberrations religieuses et supersticieuses [sic] les plus grégaires » (Alexis 1956b : 29).

Louis Maximilien, une dizaine d'années plus tôt, avait débuté son ouvrage sur le vodou en ces termes : "Aucun esprit de prosélytisme n'est contenu dans ces écrits, car le Vodou, certainement, n'est pas un moyen de civilisation. Son temps, il y a déjà bien des siècles, est révolu» (Maximilien 1945 : XXIII). Lui qui s'était déjà penché sur la musique vodou avec Werner Jaegerhuber, perçoit les cérémonies comme "un véritable drame sacré, simple et logique dans sa composition » (ibid.: 35). Il y voit là « une source jaillissante d'éléments d'art dramatique pour un artiste qui voudrait les comprendre et les changer. Il en sortirait un théâtre populaire [...]. Et aucun doute ne peut être sur l'avenir de ce théâtre qui, dominé par la religion, débuterait dans la ligne classique par excellence : les Mystères ». L'auteur suggère que « Des rapports harmonieux de parties pourraient être dégagés de ces mystères qui, transformés par l'art, éclateraient de splendeurs... » (ibid: 36-37). Il pose là les fondements de ce qui va être conceptualisé sous le nom de "préthéâtre $\aleph^{38}$ et d'ethnodrame ${ }^{39}$. Lorsque Franck Fouché, pensera le projet d'un "théâtre populaire ", dans le prolongement de l'esthétique du merveilleux de Jacques Stephen Alexis, c'est à cette notion de "pré-théâtre » qu'il recourra (Fouché 1976). MichelPhilippe Lerebours (1989, I : 263-308) qui s'est lui aussi fondé sur la théorie d'Alexis pour définir «Une esthétique nouvelle» en matière de création plastique, s'inspirera de 
Fouché pour affirmer que le vodou offre un "pré-art", "cet état d'avant l'Art» (Lerebours 1992 : 98). Les formes d'expressions plastiques du vodou sont perçues comme une réserve de matériaux bruts et non comme relevant d'un univers de création à part entière, spécifique, autonome. Le discours exclusiviste, qui a fourni la version longtemps dominante de l'haïtianité artistique, synthétisée dans l'équation art haïtien = art naïf = art vodou, ne conçoit pas non plus cette autonomie. Elle a une portée homogénéisante qui réduit la diversité des langages plastiques. En tout cas, les deux conceptions occultent l'un des acquis des bouleversements survenus à partir des années 1940, à savoir la visibilité des différents domaines de création existant et ayant existé parallèlement aux beaux-arts. Il y a bien un domaine de langages plastiques propres au vodou. Révélé dès le début des années 1940 à une école haïtienne d'ethnologie qui n'a pas su le constituer en un véritable objet d'études, il est aujourd'hui de mieux en mieux exploré, notamment par des chercheurs états-uniens ${ }^{40}$ et, en Haïti, à travers la collection, de plus en plus connue, de Marianne Lehmann. Il est constitué d'un ensemble d'objets bien spécifiques, créés ou appropriés, puis intégrés selon des procédures définies, évalués sur la base de critères établis et auxquels sont assignées des fonctions particulières. Autant de facteurs qui différencient nettement cette production d'œuvres picturales ou sculpturales non destinées aux cultes, et cela même lorsqu'elles sont celles d'artistes vodouisants.

\section{BIBLIOGRAPHIE}

ALEXIS, Jacques Stephen

1956a « Du réalisme merveilleux des Haïtiens », Présence africaine, 8-10 : Premier Congrès international des écrivains et artistes noirs : 245-271.

$1956 \mathrm{~b}$ « Contribution à la table ronde sur le folklore et le nationalisme », organisée par le Cercle Trianon, le 2 janvier 1956, Optique (Port-au-Prince), juin : 25-34.

AUBOURG, Michel

1951, Haïti préhistorique. Mémoires sur les cultures précolombiennes Ciboney et Taïno. Port-au-Prince, Imprimerie de l'État.

BASTIEN, Auguste Rémy

1944a «Archéologie de la baie de Port-au-Prince (Rapport préliminaire) », Bulletin du Bureau d'ethnologie $3: 33-39$.

1944 b « Peintures et peintres », Cahiers d'Haïti 2 (1) : 30-33.

1986 Le Paysan haïtien et sa famille. Vallée de Marbial. Paris, Karthala (1re éd. 1951).

BÉGOT, Danièle

1988 « Peinture et identité : l'imaginaire du paysage dans la peinture cubaine du XIX siècle et dans la peinture haïtienne indigéniste ", in Cuba et les Antilles. Actes du colloque de Pointe-à-Pitre (3-5 décembre 1984) organisé par le Centre interuniversitaire d'études cubaines et le Centre d'études et de recherches caraïbéennes. Bordeaux, Presses universitaires de Bordeaux : 89-104. BLONCOURt, Gérald \&NADAL GARDÈRE, Marie-José 1986, La Peinture haïtienne - Haitian Arts. Paris, Nathan. BOISSEL, Jean 
1972, Victor Courtet (1813-1867), premier théoricien de la hiérarchie des races. Contribution à l'histoire de la philosophie politique du romantisme. Paris, PUF.

BRETON, André

1965a « Hector Hyppolite » (1947), in Le Surréalisme et la peinture. Paris, Gallimard : 308-312.

$1965 b$ « Genèse et perspective artistiques du surréalisme » (1941), in Le Surréalisme et la peinture... : 49-82.

1991 L’Art magique. Paris, Phébus (1re éd. 1957).

BRETON, André \& DUCHAMP, Marcel

1947, Exposition internationale du surréalisme. Le surréalisme en 1947. Paris, Pierre à feu-

A. Maeght Brown, Karen McCarthy, 1976, The "Veve" of Haitian Vodou : A Structural Analysis of Visual Imagery. Philadelphia, Temple University, Ph. D. dissertation.

CASTERA-FILS, Georges

1997 « L'indigénisme haïtien, un point de vue contradictoire », Notre Librairie, 132 : Littéra-ture haïtienne de 1960 à nos jours : 76-89.

CÉLIUS, Carlo A.

1996 « Art plastique en Haïti au XIXe siècle. Jaymé Guilliod en 5 lettres et 20 dessins ", Pour Haïti, $23: 30-34$.

2000 « Les enjeux de la représentation. Portraits de noirs et de mulâtres pendant la révolution à Saint-Domingue (1789-1804) », in Bertas Ares Queija \& Alessandro Stella, eds, Negros, Mulatos, Zambaigos. Derroteros africanos en los mundos ibéricos. Sevilla, Escuela de estudios hispanoamericanos - Consejo superior de investigaciones científicas : 313-360.

2001 L'Avènement de l'art naïf en Haïti. Discours institué et nouvelle approche. Paris École des hautes études en sciences sociales, thèse de doctorat.

2004 « L'avènement de l'art naïf en Haïti. La portée instauratrice d'un jugement esthétique », Revue d'art canadienne / Canadian Art Review, 29 : à paraître.

CONSENTINo, Donald J., ed.

1995 Sacred Arts of Haitian Vodou. Los Angeles, Fowler Museum of Cultural History.

CORNEVIN, Robert

[1973] Le Théâtre haïtien, des origines à nos jours. [Montréal], Léméac.

COURTET DE L'ISLE, Victor

1847 « Iconographie de la race humaine (premier article) », L'Illustration, $241:$ 88-90.

1849 Tableau ethnographique du genre humain. Ouvrage couronné de 32 gravures, représentant les types des peuples tant anciens que modernes. Paris, Arthus Bertrand.

DELPECH, François Séraphin

1832 Iconographie des contemporains, ou, Portraits des personnes dont les noms se rattachent plus particulièrement, soit par leurs actions, soit par leurs écrits, aux divers événements qui ont eu lieu en France, depuis 1789, jusqu'en 1829. Paris, Chez l'Auteur, 2 vol.

DENIS, Lorimer \& DUVALIER, François 
1968 « L'ethnie haïtienne peut-elle demander aux civilisations de l'Afrique noire des directives politiques, artistiques ou religieuses ? Réponse à M. Auguste Fabius ", in François Duvalier, Cuvres essentielles, 2e éd., revue et augmentée. Port-au-Prince, Presses nationales d'Haïti (« CEuvres essentielles »), I : 209-216. [Article initialement publié dans Le Nouvelliste, 10-11 septembre 1936.]

DESLILE, Philippe

2003 Le Catholicisme en Haïti au XIX siècle. Le rêve d'une "Bretagne noire » (1860 - 1915). Paris, Karthala (« Mémoire d'églises »).

DORMILUS, Arnold

1994 « Répertoire des Bulletins et Publications du Bureau national d'ethnologie », Bulletin du Bureau national d'ethnologie, ${ }^{\circ}$ spécial 1987-1992: 114-124.

DROT, Jean-Marie

1974, Journal de voyage chez les peintres de la fête et du vaudou en Haïti. Genève, Skira.

DROT, Jean-Marie, s. dir.

1988 Haïti: Art naïf, art vodou, catalogue de l'exposition qui s'est tenue au Grand Palais. Paris-Rome, Edizioni Carte Segrete.

DUVALIER, François

1968a CEuvres essentielles. Port-au-Prince, Presses nationales d'Haïti (« Æuvres essentielles »).

1968b Souvenirs d'autrefois (bric-à-brac), 1926-1948. (publié sous le pseudonyme Abderrahman). Port-au-Prince, Presses nationales d'Haïti.

FERNARD-PRESSOIR, Charles

1947 Débats sur le créole et le folklore. Afriques grises ou Frances brunes? Langue, races, religion et culture populaires. Port-au-Prince, Imprimerie de l'État.

FIRMIN, Anténor

1885 De l'égalité des races humaines. Paris, Librairie Cotillon.

Fondation Culture Création

1995 Cinquante années de peinture en Haïti, 1930-1980. Port-au-Prince, Fondation culture création, vol. I.

FOUCHÉ, Franck

1976 Vodou et théâtre. Pour un nouveau théâtre populaire. Montréal, Éditions Nouvelle optique.

GIORDANI, Raymonde

1987 L'Anthropologie indigène: état de la question, essai d'application. Québec, Université Laval, mémoire de maîtrise.

GOLDMAN, Édouard

1926 Vers le passé suivi de: À propos de l'Exposition et à la mémoire de Boisrond Tonnerre. Port-auPrince, Bernard \& Co. Imp.

GRIAULE, Marcel

1947, Arts de l'Afrique noire. Paris, Du Chêne. 
HERSKOVITS, Melville J.

1937 Life in a Haitian Valley. New York, London, Alfred A. Knopf.

1967 Les Bases de l'anthropologie culturelle, trad. par François Vaudou. Paris, Payot (« Petite Bibliothèque »).

HOFFMANN, Léon-François

s.d. Bibliographie des œuvres de Jean Price-Mars.Port-au-Prince, Imp. des Antilles.

HURBON, Laënnec

1985 Le Barbare imaginaire. Sorciers, zombis et cannibales en Haïti. Paris, Les Éditions du Cerf ( Sciences humaines et religions »).

JAMIN, Jean

1999 « Antilles, Haïti, 1948 », in Francis Marmande, s. dir., Bataille-Leiris. L'intenable assentiment au monde. Paris, Belin (« L'extrême contemporain ») : 11-20.

KERBOULL, Jean

1977 Le Vodou, pratiques magiques. Paris, Belfond.

LAROCHE, Maximilien

1978 L’Image comme écho. Montréal, Éditions Nouvelle optique.

LE BRIS, MICHEL, s. dir.

2004 Vaudou, catalogue de l'exposition présentée à l'abbaye Daoulas, 27 juin 2003-11 janvier.

Paris, Hoëbeke.

LEIRIS, Michel

1989 La Possession et ses aspects théâtraux chez les Éthiopiens de Gondar. Fontfroide-le-Haut, Fata Morgana (1 $1^{\text {re }}$ éd. 1958).

LEREBOURS, Michel-Philippe

1989 Haïti et ses peintres de 1804 à 1980. Souffrances et espoirs d'un peuple. Port-au-Prince, Imprimeur II, 2 vol.

1990 « Allocution », Le Nouvelliste, 27-28 octobre : 4.

1992 « Pour une nouvelle lecture de la peinture haïtienne », in Pierre Bocquet, s. dir., Un nouveau regard sur les Caraibes. Paris, Créolart Diffusion : 89-108.

LOUIS-JEAN, Antonio

[1970] La Crise de possession et la possession dramatique. [Montréal], Leméac.

MABILLE, Pierre

1945 « La fonction du peintre », Studio No 3 Bulletin du Centre d'art (Port-au-Prince), I (1): 5-6.

1988 « Au pays du vaudou, peinture haïtienne », in P. Mabille, Conscience lumineuse, conscience picturale, ed. et intro. par Jacqueline Chénieux-Gendron \& Rémy Laville. Paris, José Corti : 161-162 (1re publ. in Album du Figaro, Paris, 1947, n 12).

MAINGUENEAU, Dominique

1984 Genèses du discours. Bruxelles-Liège, P. Mardaga. 
MALRAUX, André

1976 L'Intemporel. Paris, Gallimard.

MANGONÈs, Edmond

1943a « Numismatique haïtienne », Cahiers d'Haïti, 3 : 24-27.

1943b « Numismatique haïtienne », Cahiers d'Haïti, 5: 58-61.

MANGONÈs, Edmond \& MAXIMILIEN, Major Louis eds

1941 L'Art précolombien d'Haïti. Catalogue de l'exposition précolombienne organisée à l'occasion du IIIe Congrès des Caraïbes. Port-au-Prince.

MARS, Louis

1955 La Crise de possession. Essais de psychiatrie comparée. Port-au-Prince, Imprimerie de l'État («Bibliothèque de l'Institut d'ethnologie ») (1re éd. 1946).

1966 « Les crises de loas, les hiéroglyphes cinétiques et l'ethnodrame », Revue de la Faculté d'ethnologie, 11: 22-25.

1979a «L'ethnodrame », Le Nouveau Monde (Port-au-Prince), supplément du 11 février.

1979b « Métamorphose. Religion et théâtre », Le Nouveau Monde, supplément du 20 mai.

1979c « L'ethnodrame. La religion dramatique », in Hommage posthume à Léon Gontran Damas

(1912-1977). Paris, Présence africaine : 290-297.

MARTY, Anne,

2000 Haiti en littérature. [Coulonges-les-Sablons], Éditions La Flèche du Temps / Paris, Organisation internationale de la francophonie - Maisonneuve \& Larose (« Littératures d'Afrique et de la Caraïbe »).

MAXIMILIEN, Louis

1943 «Quelques apports indiens dans la vie haïtienne », Cahiers d'Haïti, 5: 42-47.

[1945] Le Vodou haïtien. Rite radas-canzo, préface de Pierre Mabille. Port-au-Prince, Imprimerie de l'État.

1947 « Hector Hyppolite », Aya Bombé (Port-au-Prince), 5-6 : 25, 29.

MÉTELLUS, Jean

1989, Haïti, une nation pathétique. Paris, Denoël.

MÉTRAUX, Alfred

1944 « Jacques Roumain, archéologue et ethnographe », Cahiers d'Haïti, II (4) : 23-24, 26.

1955 « La comédie rituelle dans la possession ", Diogène, 11 : 26-49.

1957 Haïti: la terre, les hommes et les dieux. Neuchâtel, Éd. de la Baconnière.

1989 Le Vaudou haïtien. Paris, Gallimard (« Tel ») (1re éd. 1958).

MORISSEAU-LEROY, Félix

1955a «Introduction à la peinture haïtienne », Reflets d'Haïti, 1: 7.

1955b «Le foyer a bougé », Reflets d'Haïti, 10: 1.

PAILLÈRE, Madeleine 
1975 Hector Hyppolite, Lucien Price. Port-au-Prince, Société des Amis du Musée d'art haïtien du Collège Saint-Pierre (« Collection d'histoire de l'art. Peintres d'Haïti », 1).

PAUL, Emmanuel C.

1949 L'Ethnographie en Haïti: ses initiateurs, son état actuel, ses taches et son avenir. Port-au-Prince, Imprimerie de l'État.

1962 Panorama du folklore haïtien: présence africaine en Haïti. Port-au-Prince, Imprimerie

de l'État,

PETERS, Dewitt

1945 « Pour saluer une naissance », Studio N³. Bulletin du Centre d'art (Port-au-Prince), I (1) : 3-4.

1947 « Haiti’s Primitive Painters », Harper's Bazar, 81: 104-105, 159.

PINCHINAT, Max Léo

1949a « Réflexions sur la peinture », Le Nouvelliste (Port-au-Prince), 6 octobre : 1-3; 14 octobre : $1-3$.

$1949 b$ « Art et Phrases », Conjonction (Port-au-Prince) 21: 51-53 ; 22: 37-39 ; 23: 38-40 ; 24: 64-66.

1957 « La volonté de grandeur », présentation de l'exposition Peintures de Paris et peintures récentes, au Palais des Beaux-Arts, Section des Palmistes, Cité de l'exposition, 24 février-

24 mars.

1958a « Propos sur la peinture haïtienne », Présence africaine, 20 : 104-111.

1958b « Réflexions sur l'art haïtien ». Entretien avec Gérard Latortue, Haïti-Rencontres, Bulletin de liaison des étudiants haïtiens à l'étranger (Paris), 1 : 33-36.

1962 « Haïti le pays aux quatre visages. Max Pinchinat ou l'acceptation d'une véritable

"haïtiennité" ", Afrique (Paris), 18: 72-74. (Extraits repris dans Le Nouvelliste, Port-au-Prince,

15 avril 1964.).

PRESSOIR, Charles Fernand

1947, Débats sur le créole et le folklore. Afriques grises ou Frances brunes? Langue, race, religion et cultures populaires. Port-au-Prince, Imprimerie de l'État.

PRICE, Lucien

1946a «Le Centre d'Art », Conjonction (Port-au-Prince), $6: 24-26$.

$1946 \mathrm{~b}$ «Les expositions du mois », Studio No 3 (Port-au-Prince), I (3): 7-10. [1. Exposition Bottex, p. 7; 2. Exposition Turnier-Borno-Dupoux, pp. 8-10.]

PRICE-MARS, Jean

1939 « Pour servir à l'histoire de l'évolution de la pensée haïtienne. Une mise au point », Les Griots (Port-au-Prince), 3 (3): 441 - 442.

1951 « L'état social et la production littéraire en Haïti », Conjonction (Port-au-Prince), 34 : 49-55.

1953 « Antoine Innocent ethnographe » (Discours du 29 mai 1949, à l'occasion du Jubilé d'Antoine Innocent), Conjonction, 48: 37-45.

1956 « Survivances africaines et dynamisme de la culture noire outre-Atlantique », Présence africaine, 8-10: Premier Congrès international des écrivains et artistes noirs : 272-280. 
1959a « Arts, littérature et culture » (1953), in De Saint-Domingue à Haïti. Essai sur la culture, les arts et la littérature. Paris, Présence africaine : 73-119.

1959b « Essai sur la littérature et les arts haïtiens de 1900 à 1957 », in De Saint-Domingue à Haïti... : 9-71.

1998 Ainsi parla l'oncle: essais d'ethnographie. Port-au-Prince, Bibliothèque nationale d'Haïti (1re éd. 1928).

2001 « De l'esthétique dans les races », in La Vocation de l'élite. Port-au-Prince, Presses nationales (« Patrimoine ») : 251-276 (1re éd. 1919) (1re publ. in La Nouvelle Revue, Cap-Haïtien, 1er septembre 1907).

RAMSEY, Kate

2002 « Without One Ritual Note: Folklore Performance and the Haitian State, 1935-1946 », Radical History Review, 84 : 7-41.

RIGAUD, Milo

1974 Vè-vè. Diagrammes rituels du vaudou. Éd. en français-anglais-espagnol. New York, French and European Publications, Inc.

RODMAN, Selden

1948 Renaissance in Haiti. Popular Painters in the Black Republic. New York, Pellegrini \& Cudah.

1974 The Miracle of Haitian Art. Garden City, NY, Doubleday.

1988 Where Art is Joy. Haitian Art: The Firsts Forty Years. New York, Ruggle de Latour.

ROMAIN, Jean-Baptiste

1978 Africanismes haïtiens. Compilations et notes. Port-au-Prince, Imp. M. Rodriguez.

ROUMAIN, Jacques

2003 CEuvres complètes. Éd. coordonnée par Léon-François Hoffmann. Madrid, Allca XX-Unesco.

(«Archivos » 58).

ST JEAN, Serge

1973 Hector Hyppolite, une somme. Port-au-Prince, Chez l'Auteur.

SAINT-LOUIS, Fridolin

2000 Le Vodou haïtien : reflet d'une société bloquée. Paris, L'Harmattan.

SAINT-RÉMY, Joseph

1853 Mémoires du Général Toussaint-L'Ouverture : écrits par lui-même pouvant servir à l'histoire de sa vie [...] avec un appendice contenant les opinions de l'empereur Napoléon 1er sur les événements de SaintDomingue. Paris, Pagnere.

SAVAIN, Pétion

1936 « De l'avenir et de l'intégration de la peinture haïtienne dans la peinture moderne », L'Assaut. La voix de la génération de l'occupation, 2: 45-47.

SCHAEFFNER, André

1947-1948 « Le Pré-Théâtre », Polyphonie, 1: Le théâtre musical: 7-14.

SEABROOK, William B. 
1929 The Magic Island, ill. with drawings by Alexander King and photographs by the Author. New York, The Literary Guild of America.

SYLVA, Marcello de

1938 « Pétion Savain, un moment de la peinture haïtienne », Les Griots (Port-au-Prince), I (1):

$72-76$.

THOBY-MARCELIN, Philippe

1934 « L'exposition Savain », Le Nouvelliste (Port-au-Prince), 22 juin: 2.

1945 « L'exposition du mois », Studio $N^{\circ} 3$, I (1) : 7-9.

1956 Panorama de l'art haïtien. Port-au-Prince, Imprimerie de l'État.

THOBY-MARCELIN, Philippe \& CHENET, Jean

1948a « La double vie d'Hector Hyppolite, artiste et prêtre vodou (extraits) », Conjonction (Portau-Prince), 16: 40-44.

1948b « La double vie d'Hector Hyppolite... », Conjonction, 17: 37-41.

THOMPSON, Robert Farris

1984 Flash of the Spirit, African and Afro-American Art and Philosophy. New York, First Vintage Books. TROUILLOT, Michel-Rolph

1986 Les Racines historiques de l'État duvaliérien. Port-au-Prince, Éditions Henri Deschamps.

1993 « Jeux de mots, jeux de classe. Les mouvances de l'indigénisme », Conjonction, 197 :

L'indigénisme: 29-41.

VAN GENNEP, Arnold

1943 Manuel de folklore français contemporain. Paris, Éditions Picard.

VASTEY, Pompée \& VALENTIN, baron de

1816 Réflexions sur une lettre de Mazères ex-colon français adressée à M. J. C. L. Sismonde de Sismondi, sur les Noirs et les Blancs, la civilisation de l'Afrique, le royaume d'Hayti, etc., Cap-Henry, P. Roux.

YELVINGTON, Kevin

1999 « The Invention of Africa in the Caribbean: Political Discourse and Anthropological Praxis, 1920-1940 ", contribution présentée au School of American Research Advanced Seminar, From Africa to the Americas: New Directions in Afro-American Anthropology, qui s'est tenu a Santa Fe, New Mexico, 10-15 avril, ms.

\section{NOTES}

1. Claude Souffrant, "Jean Price-Mars et sa révolution culturelle », Haïti en marche, 15-21 juin 1988 , p. 12.

2. La question de l'influence de Price-Mars sur les écrivains de la Revue Indigène n'est pas nouvelle. Price-Mars, lui-même, avait jugé nécessaire de faire le point dès 1939. Dans un article paru dans la revue Les Griots, il revendique l'antériorité de sa démarche et l'impact éventuel de sa réflexion sur ces écrivains.

3. Le qualificatif de naïf n'est pas admis de tous les chercheurs. J'ai justifié ailleurs le choix cette appellation. Cf. Célius 2001, 2004. 
4. Ce que reconnaît Price-Mars lui-même (1951).

5. Cf. Iconographie des contemporains. Depuis 1789, jusqu'en 1829, publié par F. S. Delpech, Paris, Chez l'éditeur, 1832, 2 vol. Le portrait de Toussaint figure dans le second volume. Sur le rapprochement entre les tables de physiognomonie et ce portrait, voir Célius (2000).

6. Ces deux œuvres sont reproduites et commentées dans Fondation culture création (1995, I : 26 et 29).

7. Sur Victor Courtet de l'Isle, voir Boissel 1972.

8. Voir en particulier, «De la beauté dans les races humaines" (Firmin 1885: 269-288), et «Évolution esthétique des noirs haïtiens », (ibid. : 288-301).

9. Jean Price-Mars 1998 («De l'esthétique dans les races», initialement publié dans La Nouvelle Revue, Cap-Haïtien, $1^{\mathrm{er}}$ septembre 1907, pp. 12-20, cet article a été repris dans La Vocation de l'élite, dont la première édition date de 1919).

10. Il est à noter que les dessins figurant dans cet ouvrage n'ont jamais été reproduits dans les éditions et rééditions françaises, à la différence de l'édition allemande dont j'ai eu connaissance ( Geheimnisvolles Haiti Rätsel und Symbolik des Wodu-Kultes, München, Matthes \& Seitz, 1982). Quelques-uns sont reproduits dans Consentino (1995).

11. Le courant d'art naïf est déjà constitué et sa promotion en Haïti obtient l'appui de plusieurs personnalités représentant les instances de légitimation de la modernité artistique, comme René d'Harnoncourt du Musée d'art moderne de New York, ou André Breton, chef de file du surréalisme; sa production est appréciée sur le marché de l'art surtout états-unien, en pleine expansion et prêt à accepter ces formes de création.

12. Voir Peters $(1945,1947)$ et Mabille (1945, 1989 [1947]).

13. Cf. entre autres «Painting Priest ", Time, New York, 6 janv. 1947, p. 44.

14. «Douze toiles » d'après Bloncourt \& Nadal Gardère (1986: 16), «Cinq, à huit dollars chacune », selon Rodman (1948: 60).

15. Breton \& Duchamp (1947). Trois œuvres d'Hyppolite sont reproduites dans ce catalogue: Papa Lauco (la toute première planche de l'ouvrage), Chez la gourgandine et Une prostituée (planche XXIV).

16. André Breton (1965a [1947]). Pour un commentaire détaillé de ce texte, cf. Célius (2001: 122-147).

17. Par exemple, de la liste de ses œuvres établie par Serge St. Jean (1973) (180 pièces, chiffre qu'il faudrait revoir à la hausse, estime, avec raison, Michel-Philippe Lerebours), moins de $50 \%$ des titres renvoient explicitement au vodou.

18. Dans «Survivances africaines...», Price-Mars (1956: 279) énumère des éléments manifestes de la présence africaine en Haïti et ajoute: «Quoi qu'il en soit, l'Afrique, de ce côté-ci de l'Atlantique, comme ailleurs, a inspiré une prodigieuse floraison d'arts plastiques qui a bouleversé le monde comme une révolution ». Aucun doute que l'orateur parlait d'Haïti. C'est d'ailleurs pour redire les origines africaines de «cette créativité des peintres haïtiens » que Jean Métellus a repris ce passage (1987: 151-152). Il convient de souligner que contrairement à ce qu'il fait pour les autres éléments inventoriés, Price-Mars n'a pas étayé de commentaires qui rendraient moins allusive son affirmation au sujet de la production plastique. Il a évité de nommer la peinture naïve. Ce qui confère à sa comparaison le même rapport distancié établi avec les arts d'Afrique et l'art moderne occidental.

19. «Sapattes: sorte de sandales » [note de Price-Mars].

20. Cf. Alfred Métraux (1957: 50-53) ; Bastien (1985 [1951] : 96) qui a mené ses enquêtes au même endroit, à la même époque, dans le cadre du même projet que Métraux, écrit : « Autrefois, en des temps plus heureux, on écrivait cette lettre sur un papier spécial, brodé, acheté à Jacmel. De nos jours, une simple feuille de papier fait l'affaire. » Métraux, quant à lui, reproduit un de ces papiers spéciaux. 
21. Price-Mars (1998 [1928]: 176) écrit : «Il semblerait qu'une certaine sensibilité commune à la race, voire un certain tour de langue, une certaine conception de la vie très propre à notre pays dont un écrivain de talent marquerait ses ouvrages sans que ses personnages soient haïtiens, ne manquerait point de leur donner le caractère indigène que notre critique réclame. Mais, à côté de tout cela, il faudrait quelque chose d'autre qui soit plus grand, plus vrai de vérité humaine et haïtienne, il faudrait que la nature des œuvres fut tirée quelquefois de cette immense réserve qu'est notre folklore, où se condensent depuis des siècles les motifs de nos volitions, où s'élaborent les éléments de notre sensibilité, où s'édifie la trame de notre caractère de peuple, notre âme nationale. »

22. Position qu'avait déjà adoptée M. Laroche dans « La question du point de vue » (1978: 9-15).

23. De Paul Sébillot dans la Revue des traditions populaires : [Catalogue sommaire illustré, de] « La section des Traditions populaires à l'Exposition des arts de la Femme », t. VIII, 1892, pp. 457-473 ; «Les traditions populaires et les peintres romantiques au Salon », t. V, 1890, pp. 289-294 (Salons de 1819 à 1840 inclus) ; "L'iconographie fantastique», t. IV, 1889, pp. 579-588, t. V, 1890, pp. 338-352 ; "Superstitions iconographiques: 1. Les portraits RTP », t. I, 1886, pp. 349-354; "Superstitions iconographiques: 2. Les statues», t. II, 1887, pp. 16-23; "Superstitions iconographiques: 3 . Manies et superstitions des peintres; 4 . Les modèles; 5 . La peinture et le mauvais œil, t. II, 1887, pp.270-272.

24. Cf. Duvalier [alias Abderrahman], «Esthétique» (1926?) (1968: 25-28), «Du mot d'“Africain" " (L'Action nationale, 11 juillet 1934) (ibid. : 53-55), « Au cours de la durée les destins se rencontrent » (L'Action nationale, 27 juillet 1934) (ibid. : 77-79).

25. Cf. «La culture populaire. De la poésie, du chant et des danses dans l'esthétique vodouesque » (conférence prononcée le 27 avril 1952 à Port-au-Prince, à l'école République du Venezuela) (Duvalier 1968a, I : 249-276).

26. Breton raconte aussi (1965a) : « Un jour que je sollicitais son opinion sur les toiles de Wifredo Lam dont se préparait une exposition au Centre d'art, il afficha pour lui un vif et déférent intérêt tout en se récusant légèrement parce qu'à ses yeux c'était de la "la magie chinoise" par opposition à la "magie africaine" qu'il sous-tendait être son fait [Wifredo Lam était né de père chinois et de mère cubaine noire]. "

27. Alfred Métraux (1989: 13). Métraux donne une autre version, où il lie ses propositions à Roumain à la protection des sites archéologiques (1944).

28. Cf. Roumain (2003). Voir les travaux scientifiques de Roumain (pp. 1009-1160) ainsi que les articles de Jean Michael Dash («Jacques Roumain romancier», pp. 1359-1377) et d'André Marcel d'Ans («Jacques Roumain et la fascination de l'ethnologie », pp. 1378-1428). Sur les activités de recherche de Roumain, voir aussi les rapports d'activités du Bureau dans le Bulletin du Bureau d'ethnologie, 1943, n² 2, pp. 4-7; 1944, n 3, pp. 5-8; décembre 1946, sér. 2, n 1, pp. 8-11; Rémy Bastien, « Archéologie de la baie de Port-au-Prince (Rapport préliminaire) », 1944, n 3, pp. 33-39. 29. En 1947, C. Fernard-Pressoir soutient leur origine africaine (1947 : 48). Emmanuel C. Paul estime, en 1949, qu'en introduisant cette référence, Louis Maximilien complique inutilement la genèse du vodou pour ceux qui doutent encore de l'influence prépondérante de l'Afrique. Cf. Paul (1949 : 26 ; voir aussi 1962 : 300). K. Mc C. Brown quant à elle admet leur origine africaine (1976). R. F. Thompson (1984: 188) n'a aucun doute non plus sur une telle provenance. Alfred Métraux pense qu'ils sont d'origine dahoméenne mais qu'ils doivent leur style aux ferronneries et aux broderies du XVIII ${ }^{\mathrm{e}}$ siècle français (Métraux 1989 [1958]:148). Jean Kerboull (1977) insiste sur l'apport de la magie européenne et de la franc-maçonnerie. S'appuyant sur la présence attestée d'esclaves islamisés dans la colonie, Michel-Philippe Lerebours (1989, I: 53) n'exclut pas l'influence même indirecte de l'art musulman.

30. Cf. la liste des mémoires soutenus à la Faculté d'ethnologie d'Haïti de 1959 à 1969, parue dans la Revue de la Faculté d'ethnologie, 1970, n 15.

31. Max Benoît, s. dir., Cahier de folklore et des traditions orales d'Haïti, Cenahfotro-Cinecutoh, 1980. 
32. Le tableau que Romain reproduit n'est pas fidèle à celui qui figure dans Herskovits (1967). Entre autres différences, pour la rubrique « art », il est indiqué « (?), pas d'indication » alors qu'il est mentionné « (d), un peu africain » dans Herskovits.

33. Tige de fer surmontée d'un petit plateau rond, plantée devant l'autel et servant de bougeoir.

34. Talisman d'un genre particulier: sacoche de soie portant des ornements et d'apparence anthropomorphique.

35. M. L. Pinchinat (1949a, 1949b, 1957, 1958a, 1958b, 1962).

36. Sur la distinction entre univers discursif, espace discursif et formations discursives, cf. Maingueneau (1984).

37. Voir entre autres de L. Price (1946a, 1946b), Lerebours (1989), Thoby-Marcelin (1956) et de M. Paillère (1975).

38. Cf. L. Mars (1955 [1946]) qui établit très tôt un rapprochement entre l'espace rituel du vodou, la possession et le théâtre. Cf. A. Métraux (1955); A. Schaeffner (1947-1948), M. Leiris (1989 [1958]). L'influence d'Haïti sur l'élaboration de cet ouvrage est mise en évidence par J. Jamin (1999).

39. L. Mars (1966), article repris, avec un autre texte dans Cornevin ([1973]: 190-192), Mars (1979a, 1979b, 1979c) cf. aussi A. Louis-Jean ([1970]).

40. Cf. entre autres Consentino (1995). Plusieurs articles de ce catalogue sont repris et traduits dans M. Le Bris (2004).

\section{RÉSUMÉS}

L'avènement de l'art naïf en Haïti dans les années 1940 bouleverse le monde des langages plastiques du pays. Il survient au moment où s'affirme le tournant ethnologique et apparaît comme une de ses multiples fécondations. Or deux faits se révèlent à l'analyse : d'une part le jugement esthétique qui instaure le nouveau genre artistique en Haïti ne procède pas de l'esthétique indigène prônée par l'école haïtienne d'ethnologie, d'autre part celle-ci éprouve de grandes difficultés à accompagner cet art, à le penser ou, tout simplement, à l'approcher. En fait, on est en présence de deux ordres de choses distincts advenus dans le cadre d'un même paradigme. Une parenté qui a facilité l'établissement d'une relation d'engendrement entre eux. D'autant plus que l'ethnologie propose une caractérisation globale de la société, à partir de laquelle on a pu justifier et élaborer des explications du phénomène artistique. Le discours haïtien sur l'art y a recouru, ce qui lui a valu sa force autant que sa faiblesse.

The advent of naive art to Haiti in the 1940s upset the «world of plastic language» there. Naive art arose at an «ethnological turning point» and emerged as one of its multiple fecundations. An analysis brings to light two facts. For one thing, the aesthetic judgement that established this new artistic genre in the country did not proceed from the native aesthetics advocated by the Haitian school of ethnology. For another, this school had a difficult time keeping abreast of this genre, thinking about it or even approaching it. Two distinct phenomena were happening within a single framework that made it easy to establish a «kinship» between the two, especially since ethnology proposed a global view of society that served as the basis for working out and justifying explanations of the artistic phenomenon. Haitian «discourse» about art referred to this basis with its strong and weak points. 
INDEX

Mots-clés : africanismes, art naïf, folklore, haïtianité, indigénisme, jugement esthétique, primitivisme, race

Keywords : africanism, esthetic appreciation, indigenism, naive painting, primitivism

\section{AUTEUR}

CARLO AVIERL CÉLIUS

Université Laval, Chaire d'histoire comparée de la mémoire-CÉLAT, Québec, Canada, carloa.celius.1@ulaval.ca 